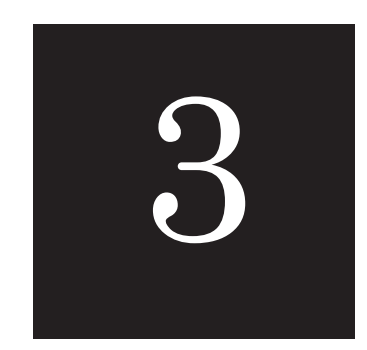

\title{
EL MAESTRO, LA ARGUMENTACIÓN EN EDUCACIÓN
}

\section{Introducción}

Es propósito identificar en los actuales términos de la educación, los prototipos argumentativos que sustentan al maestro en el ejercicio de su tarea educativa, e identificar una argumentación de cara a una concepción más abierta del ser humano, al proceso del conocimiento y a la sociedad. Este propósito implica identificar en el estado actual de las discusiones sobre la educación superior el conocimiento que el orden social moviliza, las instituciones y sujetos que requiere y genera y, finalmente, sustentar desde aquello que se identifica como el ethos propio de la educación superior, el rol que corresponde al maestro con la connotación de formador.

Las trasformaciones que sufren la educación, las comunidades cognitivas y el conocimiento reflejan cambios mucho más profundos, que van más allá de cuestiones o intereses epocales, o incidencias de medidas externas de carácter organizacional; es algo más allá que toca retos y tensiones que experimentan hoy los maestros, los alumnos y la comunidad cognitiva. 
La educación superior y las comunidades académicas que la gestionan, se incorporan en la actualidad a un caudal social sin precedentes, con rezagos de diferentes formas de argumentación y de acción educativa, rezagos que traslapan modos de ser y de actuar, rezagos de ideales clásicos como la denominada paideia para la civilidad, de aquellos ideales de la tradición racional-natural en su compromiso con la vida humana, pero también de la sociedad moderna tardía con su estrategia pragmática operacionalista, hasta llegar a una institucionalidad habitada por paradigmas como el de las ciencias sociales, la filosofía de la historia, las ciencias del espíritu, por ideas preconcebidas de hombre, por objetivaciones de la realidad y del alumno.

Esto conlleva retos a aquello que se ha convenido en denominar el ethos educativo, sobre todo a nivel superior y para lo superior. Cuando la sociedad reclama un mayor compromiso de los académicos, lo hace en razón a las necesidades de dicha sociedad en relación con su pertinencia social, y esto produce tensiones, encuentros y desencuentros en cuanto a la preservación de la libertad académica, las formas de producir y gestionar el conocimiento, el lugar y papel de los maestros, pudiendo alterar una de sus funciones sustanciales: alimentar una concepción del ser humano más ajustado a su ser.

Además, el conocimiento que se presenta como rasgo esencial del proyecto de la sociedad moderna, no tiene una correspondencia con el conocimiento que la educación superior históricamente promueve. La sociedad promueve un conocimiento que no es abordado como un proceso, sino como un producto, y como tal introduce nuevos lenguajes como competencias, talento humano, eficiencia, transferibilidad, trabajo colaborativo, sociedad del conocimiento, decisionismo, entre otros. Esto influye en la argumentación y configuración de los currículos desde una visión limitante, que puede llegar a olvidar la adquisición del conocimiento como proceso, como desarrollo del intelecto, de la voluntad, como abordaje de la verdad, como apuesta por la objetividad, dejando de lado categorías esenciales como la comprensión, la interdisciplinariedad, la crítica, la sabiduría. 
Ante los cambios de una sociedad que muestra multiplicidad de formas, sin instituciones dominantes, a no ser las del mercado, con exceso de circulación de todo tipo de objetos, de información, de sensaciones, de discursos, de promoción de distintas formas de vida, la comunidad cognitiva, los maestros se sienten incómodos, como encerrados ante una racionalidad prescriptiva, de fines preestablecidos, operacionalistas, urgidos por un Estado regulador, evaluador, de mano de un discurso de corte neoliberal.

Los maestros generan acuerdos, acomodaciones, pero también resistencias. En este contexto, se sienten y se avizoran profundos cambios en los roles del maestro en diferentes direcciones: la educación superior ante la sociedad, ante el conocimiento, el rol del estudiante ante nuevas concepciones de educación pragmatista, pero sobre todo el rol y papel del maestro ante la sociedad, ante el conocimiento, ante el alumno, ante sí mismo.

En criterio de Martha Nussbaum (2011, p. 20), estamos en medio de una crisis de proporciones que aún no hemos comprendido lo suficiente, una crisis que con el tiempo puede llegar a ser mucho más perjudicial, y no es exactamente una crisis de carácter económico, aunque la incluye, es una crisis en orden a la educación, según la autora.

Educación que cada vez se muestra más incapaz de acompañar a los ciudadanos ante la capacidad de pensar por sí mismos, poseer una mirada crítica sobre las tradiciones, comprender el tiempo presente y comprender la importancia de la democracia, la ecología, la solidaridad, lo nocivo de un ánimo de lucro sin medida, los extremismos o retrocesos temerosos al pasado, la afiliación a cuerpos de doctrina reaccionarias, excluyentes, el relativismo epistemológico que conduce a una resignación intelectual (Nussbaum, 2011, p. 20).

No se trata de recuperar el pasado, ni el establecimiento de una forma cognitiva específica, ni un orden específico de academicismo, la argumentación en educación más bien debe consistir en una forma 
nueva de abordar la pregunta por la posibilidad de una concepción más abierta de la práctica educativa adecuada para una educación superior, que sostenga unas relaciones debidas con la sociedad y sobre todo que esté sustentada en una concepción más ajustada del ser humano (Barnett, 2001). En estos propósitos el maestro ha de ocupar un lugar específico, su desplazamiento o instrumentalización ha conducido históricamente a una crisis de humanidad, como lo denominara el economista Max Neef.

No se pretende en el desarrollo de esta propuesta una descripción con carácter historicista de los discursos o argumentaciones que alientan o urgen a los maestros, sino un navegar por los picos de aquellas voces que permitan una mirada comprensiva y a la vez crítica, como búsqueda de momentos y condiciones de emergencia de acontecimientos de gestación de dominios que terminan por constituir criterios de verdad de un acontecimiento (Foucault, 1977, p. 278).

\section{Educación, una práctica histórica}

En una perspectiva socio crítica, educar no es una determinación neutral, está sustentada en autores y épocas, en construcciones argumentativas históricas que la sustentan. En criterio de MacIntyre (1994, p. 25) “la complejidad de la racionalidad, ha de incluir la historia o la historicidad que la expresa, porque como argumenta el autor, la razón y la acción humana son manifestaciones históricas”.

En el interior de la concepción y puesta en práctica de un ejercicio educativo hay movilidades o fijaciones de determinados discursos o hablas. Igual que en el pasado, hoy tenemos unos discursos y paradigmas, algunos con mayor prevalencia en la forma como se argumenta y se lleva a la práctica el acto de educar. Como ejemplo se puede señalar la lógica paradigmática que parece habitar la práctica y la argumentación en la educación. Pero habitar no es exclusividad, pues con esta conviven y perviven rezagos de otros modelos conceptuales como el instruccionismo o el construccionismo que se adaptan como metódicas 
del pragmatismo, incluyendo una conceptualización de currículo, una transmisión sobre formas de obrar y operar muy específicos. Otro tanto se puede tener con la lógica de las ciencias en el interior del discurso y práctica educativa que generó profundas deconstrucciones con las prácticas tradicionales.

La racionalidad del obrar, si es una acción de la persona, está fundada en razones con capacidad de decir por qué se obra de esta u otra manera y por esto mismo se sitúa dentro de los conflictos y tradiciones que la historia de la racionalidad devela. Se ve, por ejemplo, que la categoría formación es una categoría central para la educación y para el maestro, pero esta es entendida de muy diferentes maneras. La consecuencia de lo expresado por MacIntyre es que la racionalidad del obrar necesariamente es histórica, lo que implica que formar se diga de varias maneras, y que se requiera argumentar, dar razón para su justificación, para su realización y comprensión histórica. "Justificar significa narrar hasta donde ha llegado el argumento, historia, que lleva a afirmar la existencia no de una racionalidad, sino de diversidad de racionalidades" (MacIntyre, 1994, p. 25).

Las argumentaciones en educación observan desplazamientos que van del carácter del hombre pre y socrático al platónico-agustiniano y al aristotélico y su posterior recuperación en algunos momentos en la escolástica con Tomás de Aquino. Un segundo momento se da con el pensar cartesiano y moderno hasta el actuar emotivista y plural del hombre de la posmodernidad.

La universidad como institución es la que tal vez más incorpora en su decurso las transformaciones históricas, y a veces lo hace de forma acrítica, conectándose a fuerzas directoras emergentes, por ejemplo, la razón como principio fundante, como lo expresaba Kant (2003) en su crítica a la razón pura, otra puede ser los parámetros del mercado mundializado (Barnett, 2001), también puede ser fuerza directora el Estado como ente educador (Martínez, 2004). Como consecuencia 
de estas incorporaciones, autores como A. MacIntyre (1994), Marta Nussbaum (2011) Alain Renaut (2008) arguyen que la universidad atraviesa una fuerte crisis de identidad en su interior.

La racionalidad o argumentación se concibe como parte de un proceso sociohistórico que solo puede ser entendido y abordado en el marco de un contexto social más amplio. El proyecto moderno por ejemplo es consecuencia del proceso de racionalización de la sociedad occidental. Voces en horizontes históricos y con claves de pensamiento distintos a la visión de hoy, paradójicamente parecen dar respuestas a las preguntas actuales, de porqué el maestro y sus comunidades cognitivas actúan como actúan.

Armando Rodríguez (2008, p. 57) resalta cómo la sociedad contemporánea, que él enmarca en lo posmoderno, está ante una “infinita variedad de propuestas tendientes a calmar la inquietud existencial que caracteriza al hombre contemporáneo, que no sabe qué hacer con su tiempo, con su tiempo personal y con su tiempo epocal”. Y recurriendo a Lyotard, se dirá de este hombre contemporáneo que la vida va deprisa. Se sabe que la vida va en todos los sentidos. La insignificancia es algo propio de lo posmoderno, tanto de la cosa como de la palabra (Lyotard, 1998, p. 7). Con todo nada impide que se planteen preguntas en relación con ¿Cómo vivir? ¿Por qué?

Nuestros conflictos no son como tal vez lo fueron en el siglo pasado, de orden ideológico, parecen ser más bien consecuencia fallida de pretender hallar en las ideas asépticas y limpias, en ideas claras y distintas, como lo dijera Descartes, en la teoría pura como lo expresara Kant, motivos para agotar los límites de la inteligibilidad, para la solución de problemas del diario vivir, que dependen mucho más de nuestro carácter, dominio y posesión de sí, que de nuestra posibilidad o no de cognición teórica en sentido estricto. No se trata de resolver problemas filosóficos pasados, aunque muchos siguen teniendo vigencia. Con todo, una aproximación a estos, son un pretexto para dilucidar y orientar nuestra acción presente. 
La comprensión de las acciones humanas implica necesariamente la posibilidad del conocer (MacIntyre, 1994), y este conocer, en un momento de la historia, fue escindido por la denominada modernidad, quedando el yo pienso cartesiano como única alternativa. La necesidad de la narración en el aprendizaje, bajo el predominio de la visión cartesiana de la racionalidad, aliciente del pensamiento ilustrado, con las proclamas de libertad igualdad y fraternidad, termina desvaneciendo del campo de visión aquellos criterios del hombre burgués libertario, conllevando la pérdida de sentido, al estado de confusión y contradicción de la posmodernidad.

Ni la interpretación del mundo, ni su transformación, son actividades aisladas o distintas, máxime cuando el conocer no es pasivo, sino un producto de nuestra interacción con la realidad (MacIntyre, 1994). Tras el avance de la ciencia y la especialización del conocimiento, tanto el conocer como el actuar se han pulverizado por un saber por compartimentos disciplinares.

En criterio de MacIntyre y algunos trabajos como el dirigido por Victoria Camps (2002), invitan a navegar en aspectos del desarrollo de las cosmovisiones que han conformado la razonabilidad en Occidente, sustentando un modo determinado en el actuar humano, específicamente al identificar un quiebre hacia un pensamiento meramente funcional, operativo y técnico. Este quiebre también ha comprometido el accionar del maestro en una cierta dirección en detrimento de otras perspectivas esenciales al acto educativo como la perspectiva humanística para un desarrollo integral humano. Así, aquella pregunta práctica sobre la forma en que ha de integrarse lo que una persona es, lo que puede ser, lo que quiere ser y lo que debe ser, puede terminar fuera del apoyo que ha de dar la educación y el maestro (MacIntyre, 1994, p. 21).

Después del último esfuerzo sistemático del pensar filosófico, que lo representa la filosofía de Hegel en criterio de Victoria Camps (2002), el conocer y el actuar se diversifica en una serie de tendencias cuyo único punto de encuentro lo constituye compartir un objetivo común: 
la escisión y puesta en cuestión de los presupuestos argumentativos y metodológicos que el pensar del pasado sustentaba.

Se critica y desecha un cierto modo de hacer práctica educativa por su carácter ideológico, metafísico o simplemente especulativo, especulación vacía, inoperante, que por lo demás se tildaba de engañosa. El racionalismo, el marxismo, la filosofía analítica, y el existencialismo como filosofías del siglo $\mathrm{XX}$, por encima de sus obvias divergencias, paradójicamente encuentran un espacio común en la educación abordada eclécticamente, como era de esperarse, saltando los grandes y tradicionales conceptos, "puesto que las costumbres, los deberes y las normas se dan cargadas de subjetividad y relativismo” (Camps, 2002, p. 8).

A partir de entonces las miradas del acto educativo llevado a cabo por el maestro en su accionar, lejos han estado de encontrar su punto y han sido objeto de múltiples lecturas, donde la realidad excede su propio conocimiento y donde el discurso abstracto no da la medida de la riqueza del ser concreto. En tal intento, en la cultura del mercado académico actual, la educación y con ella el maestro, se han convertido en punto de llegada de muchos discursos que se presentan escindidos de referencias, entre ellas la del saber clásico, la del humanismo entre otros. Lo paradójico, es que ese saber clásico, lejos ha estado de desaparecer y más bien parece estar de vuelta en la denominada recuperación de la idea práctica, aunque con unas características específicas.

El motivo de esta vuelta estriba en que la razonabilidad de la acción que le es propia al maestro, no se alimenta solo de sí misma, es a su vez reflexión sobre sus épocas, a modo de combinación de historia interna y externa. Cualquier proposición que tenga que ver con una cierta forma de praxis pedagógica, ha de formularse a partir de la historia de esa praxis. Al considerar en sí las grandes figuras del pensamiento filosófico y en particular el pedagógico, no es una tarea plausible diseccionar lo que es objetivamente teoría o práctica, de lo que es epistemología o ética, o política o religión. Un discurso valorativo de las costumbres 
o de una determinada acción como la del maestro, implica a su vez, como lo indica Camps (2002, p. 11, prólogo II) "reconstruir el pasado para entenderlo en su propia atmósfera, pero también para entender el presente”, lo cual implica un acudir al amplio panorama del pasado con sus intereses y actores con las preguntas del hoy, con el propósito de la apreciación, el enfoque y el punto de vista de problemas que necesariamente inciden en la experiencia individual y colectiva que no carece de peculiaridades propias.

La visión de la práctica del maestro, emerge a priori de las mismas descripciones de la historia de esta práctica y hay una mutua relación e implicación entre estas. Siguiendo a Gómez (2001, p. 283), legitimar el pensamiento práctico en educación es “dejar ser”, es “develar”, su intrínseca necesidad de significación en el todo del pensar. La praxis es un "momento" del todo no más, tampoco menos. Legitimar teóricamente la praxis del maestro, requiere mantenerse fiel a lo que ha sido el ejercicio mismo del pensar, ante el que hay que estar atento para

evitar cualquier forma de ligereza o abandono de lo que ha sido el trasegar mismo del pensar, que puede darse bajo las sutiles formas de los caminos de la intuición, del sentimiento, de la absolutización, parcialidades, el pensamiento abstracto, el pragmatismo, el hedonismo (Rodríguez, 2008, p. 66).

La racionalidad del quehacer educativo se funda en razones, y esto hace que la propia racionalidad nos sitúe dentro de los conflictos y tradiciones que a su vez devela una determinada práctica educativa. La racionalidad del educar participa así de una fundamentación inmersa en la historia, desde allí, esta práctica se constituye como actividad de racionalizar la práctica del enseñar a otro, lo que implica que enseñar requiera argumentar, dar razón, justificar su realización y comprensión histórica. "Justificar significa narrar hasta donde ha llegado el argumento, argumento que lleva a afirmar la existencia de no una racionalidad, sino de diversidad de racionalidades” (MacIntyre, 1994, p. 25). 


\section{Argumentación clásica, dominio del método inductivo - deductivo}

La aprehensión de la realidad y el modo de actuar en ella, en el campo específico de la pedagogía y su práctica educativa, ha cursado un largo trasegar de búsqueda. Rodríguez afirma:

Nuestro tiempo no es “el tiempo de Aristóteles”, sus coordenadas espacio temporales eran distintas. Nosotros moramos en "otro tiempo”, pertenecemos a “otro tiempo”. Sin embargo, volvemos permanentemente al pensamiento aristotélico para recabar en él y rescatar de él, su verdad y su universalidad. Se trata de un retornar al qué aristotélico pero desde una distinta altitud histórico- filosófica (2008, p. 66).

La primitiva pregunta por el educar, la posibilidad de su comprensión y su vínculo con la acción del maestro, fue tarea abordada en el pasado por la filosofía, hoy es fruto de una mirada multifacética. Los testimonios aportados por la argumentación reflexiva del pasado, no solo muestran camino ya andado, sino que continúan traslapando de muchas formas las respuestas del presente, esto hace que hoy continúen tal vez los mismos interrogantes. En este sentido cualesquiera que fuesen los problemas, aún los no filosóficos y pese a la distinción de métodos para resolverlos, continuará existiendo un núcleo irreductible que permanece en casi todos ellos (Kenny, 2000).

La respuesta a aquella pregunta tan antigua como nueva de ¿cómo ha de vivir el hombre plenamente? se ha dado históricamente en una doble tensión: el bien de la persona es intrínseco a ella y consiste más en la excelencia del agente, y de otro lado, en los logros externos de su actividad u operación. Las actividades con las que se consiguen bienes externos, se encaminan también a alcanzar bienes internos, necesariamente complementarios; pero este legado del pasado clásico ha caído históricamente en una dualidad o dialéctica que ha sido a la vez, causa y manifestación de un modo específico del maestro de la modernidad. 
En efecto, un proceso educativo entendido como formativo, aborda el pensar en doble dirección, no solo como aprehensión y dominio hacia afuera, también ha de ser hacia adentro, hacia el agente que ha de ser formado en su integralidad según sus dimensiones y capacidades, como proceso auto-generativo y no solo productivo.

Los bienes externos son aquellos que pueden conseguirse de muchas maneras: haciendo una actividad u otra, haciendo bien o incluso mal una actividad. Pero si “tal es el ser, tal es el actuar”, llevó a Aristóteles a afirmar en su Metafísica, que "los que admiten la producción hasta el infinito, no ven que suprimen por este medio el bien" (Libro II, 983b-995a). Luego, una consecución solo de bienes externos como fin del acto educativo dejaría mucho que desear desde el punto de la excelencia de la persona. El legado clásico es muy claro en este asunto.

En consecuencia, lo que busca la educación es una seria colaboración con el ser del hombre, y por tanto presupone en toda su condición la persona humana que es principio y término, en última instancia, en donde la actividad humana cobra sentido, pues la naturaleza de una cosa es la misma esencia de ella, considerada como principio radical de sus operaciones propias. En consecuencia, ninguna clase de medida externa de carácter organizador en educación, por muy sensatamente pensada que esté, puede tener éxito sin una teoría fundante que sea capaz de dar una respuesta al que, al cómo y al para qué meta debemos educar. Esto explica aquello que reclamaba K. Dienelt (1980) según el cual educar requiere una teoría más profunda que permita comprender la existencia humana, una imagen válida del hombre ajustada a su ser.

Los dos mayores filósofos de la Antigüedad occidental, Platón y Aristóteles, permiten dos aproximaciones a "lo real", como estructura de un tipo de racionalidad y el cómo actuar en esa realidad. Platón, terció por un mundo eidético que determina el alma al abordar el mundo, con sus estructuras ontológicas. En Aristóteles su construcción racional es en y desde un mundo concreto, que se ha denominado realismo aristotélico (Roldán, 2010, p. 37). 
Aristóteles en la Ética a Nicómaco, distingue principios teóricos y principios para lo práctico, y estos son formulados por la inducción (en Libro VI, cap. 9 1142b, pp. 22-26). El carácter absoluto de la valoración en la acción, sugiere al hombre valoraciones de uno u otro tipo, por cuanto no se parte de una idea ya establecida, sino que ella ha de surgir en y desde la misma práctica, desde la experimentación.

Para el hombre del pasado clásico, la matriz originaria de los móviles para el actuar estuvo en la observación y su conclusión es la inducción. Aplicando esto a la disciplina o disciplinas que se interesen por la educación en cuanto tal, serán ciencias prácticas y no especulativas (Martínez, 2002). El pasado clásico concibe a la educación como una práctica, Kant, en cambio, concibe el acto educativo como el desarrollo de una idea previa. Hoy el acto educativo se concibe bajo códigos y sistemas pragmáticos, económicos, eficientistas, problémicos. Lejos quedan las razonabilidades o convenciones de praxis inductivas o deductivas, ahora el argumentar se hace desde el escenario de la racionalidad compleja.

En el pasado la lógica se presenta, con algunas excepciones, como una forma capaz de describir la esencia de ciertas estructuras de lo real. Con Aristóteles, se distinguen caminos en la comprensión de lo real: se encuentra la intuición intelectual, lo universal de las realidades empíricas, donde el intelecto humano deja de limitarse pasivamente a "recibir las impresiones sensoriales desde los objetos", y desarrolla un lugar activo por el que va más allá de las particularidades y capta la esencia en acto (Reale, 1997, p. 159). La otra línea de conocimiento es la lógica formal, enunciada por Aristóteles en la forma deductiva del silogismo. Tenemos así los dos paradigmas clásicos de la epistemología deductiva y la inductiva. Pero cada una tiene sus propios límites como lo advertía el mismo Aristóteles al señalar que estos ejercicios lógicos por sí solos no pueden dar la episteme, porque no dan garantía de verdad, pues, si las premisas son falsas también la conclusión será falsa. Hoy los científicos admiten en efecto que los métodos en las teorías sirven 
para confirmar mas no son la verdad. Para Aristóteles, la inducción es solo un grado preparatorio hacia la intuición intelectual.

La lectura de la realidad necesita en efecto de las dos miradas, tanto de la epagoghé de la que Aristóteles habla a propósito de la inducción, como de las intuiciones puras. Sería errado pensar hoy, alcanzar garantía de verdad, solo por el hecho de saber formular leyes universales partiendo de casos particulares (Reale, 1997, p. 159).

Tomás de Aquino en su argumentar, concibe la selección de bienes basado en las cualidades propias de las cosas, entre bienes plurales y heterogéneos, que son elegidos cada uno por su propio valor. Es una posición realista que no contradice su visión teológica, pues salvada la analogía con la bienaventuranza, la vida concreta se da a partir de la manifestación de diferentes formas y maneras, donde el bien supremo confiere racionalidad al acto humano particular, donde fácticamente no hay un patrón en cuyos fenómenos todos los bienes sean conmensurables, como sí ocurre en la deducción. En consecuencia, la tradición clásica es el planteamiento del dominio del método inductivo - deductivo que se puede identificar desde Aristóteles hasta comienzos del siglo XIX.

Se deriva que la naturaleza de una cosa es la misma esencia de ella, considerada como principio radical de sus operaciones propias. Así, el ser finito se estructura desde el acto, y se realiza en los actos porque mediante ellos alcanza el fin. Aquí tenemos a una persona concreta y actuante, no una abstracción de ella. Así, una vez que se medite sobre la naturaleza sustancial propia del hombre en su actuar, se echará de ver la necesidad en que se encuentra de ser completada por ciertos hábitos operativos.

El hombre, en efecto, tiene una naturaleza sustancial que difiere de las de otros vivientes y esta es sumamente abierta e indeterminada, que precisa ayuda para su perfeccionamiento; este es precisamente el espacio de la educación y del maestro. Lobatto (1994) precisa que a esta 
necesidad de ayuda para la consecución de una perfección se le ha de denominar educabilidad y esta:

es el objeto formal bajo el que se estudia la acción educativa que se aplica a trabajar bajo la formalidad de lo perfectivo del hombre, de la virtud. El acto educativo en tal sentido es una seria colaboración con el ser de la naturaleza personal y las posibilidades de alcanzar su perfección (1994, p. 520).

Perfección que hay que acompañar siguiendo el rastro y camino de su propia naturaleza.

\section{La argumentación para la acción del maestro en la modernidad, ante lo hipotético - deductivo}

Cierta forma de la argumentación en educación y, por ende, de la práctica educativa contemporánea, se entiende desde la perspectiva de un pensar, que en criterio de José Rubén Sanabria (2001, p. 35) es una lógica que "niega toda necesidad y validez de fundamento último, sea inmanente o trascendente, que explique o legitime la multiplicidad de lo real, o que funcione como criterio definitivo de la verdad teórica o axiológica". A riesgo de un ligero reduccionismo, se dirá que confluyen en estas expresiones de pensamiento una relación de conceptos y una lógica que refiere a exención de supuestos, emancipación, revolución y crítica.

El empeño por confrontar racionalidad y sentimiento, que nació en la filosofía de Hume, marcó buena parte del pensamiento occidental (Camps, 2002), consolidando una ruptura en la naturaleza unitaria del pensar. Así como el mundo mítico e inteligible de Homero y Sófocles, cedió a un intento de comprensión del mundo radicalmente novedoso y de consecuencias extraordinarias con la explicación natural del cosmos por la observación y la lógica del razonamiento, otro tanto fue el quiebre de aquella cosmovisión universal, que con su debilitamiento produjera otra ruptura: 
Se puede decir que la pedagogía tuvo un nacimiento múltiple al desmembrarse o fraccionarse la estructura piramidal y total del idioma latín, de la filosofía escolástica y de la soberanía de la Iglesia Católica. El idioma, el pensamiento y el poder político convergieron en lo que se denominó la Reforma y son ellos los decisivos para pensar la pedagogía moderna (Quiceno, 1998, p. 129).

El análisis crítico que la mente humana alcanza de los fenómenos naturales fortalece la inteligencia independiente del hombre y se debilita el poder soberano de lo trascendente. Se da un cambio de actitud escéptica, contra las creencias (Brunschwig. 2000, p. 85). Es un pensamiento especulativo que se basa en los conceptos de naturaleza, en la regularidad de la relación causa-efecto, de la que se excluye la invocación a una intervención sobrenatural, sustituida por la observación, que permite descubrir la relación causal, y el auge de la verificación experimental, que permite asegurar su regularidad y esgrimir una teoría (Quiceno, 1988, p. 130). Cuando la experiencia se reflexiona, se formula de manera universal, aprehende las causas de sus éxitos, sirve de base al saber práctico (techne) y a la ciencia teórica. Esta orientación inclinó las preocupaciones hacia la naturaleza y las formas de la racionalidad. "Sentir, hablar y organizar la naturaleza se hizo más evidente. Hablar y enseñar en lenguas distintas al latín era recorrer la prosa del mundo abierto, lo desconocido, lo incierto, lo todavía no organizado ni organizable” (Quiceno, 1988, p. 130). Este cruce de sentidos diversos conllevó a que la educación se convierta en un objeto natural, positivo racional, "la pedagogía vinculada a las ciencias naturales y a las ciencias del hombre” en criterio de Quiceno. Desde Comenio hasta Pestalozzi, las Lecciones de pedagogía de Kant, la obra básica de Herbart, Fröbel, Rousseau, están dentro de este paradigma naturalista. Este razonar, “emparejó las formas de análisis de otras ciencias, como la economía, la gramática o las ciencias de la naturaleza, con las ciencias exactas, haciendo que todas ellas empleen una misma forma de razonamiento y unos mismos procedimientos de reflexión” Quiceno (1998, p. 130). 
Pero este volcarse hacia la naturaleza humana no se agota en un contexto solamente biológico, pues mientras que los demás vivientes devienen por naturaleza eso que por naturaleza tienen el poder de devenir, no sucede lo mismo con el hombre. "La praxis humana no consiste inmediatamente en la expansión natural de disposiciones naturales, como en los demás seres vivos, sino que en cuanto humana, toma la forma de arte (tékhne), de método y, en ese cuadro, de elección deliberada” (Quiceno, p. 449).

Declarada la autonomía y la superioridad de la razón humana ante la realidad, lo real es inteligible, es decir, objeto de aprehensión intelectual. Como consecuencia no solo los dioses pueden ser una ilusión, sino también la evidencia inmediata de los sentidos, de tal forma que para descubrir radicalmente qué es lo real no puede confiarse más que en la mente humana. Este naturalismo y racionalismo dan lugar a una concepción cada vez más elaborada en explicar lo real, y también da nacimiento a una dialéctica a veces irreconciliable entre la observación sensorial y el nuevo rigor lógico. Cuanto más se desarrolla la capacidad de un juicio crítico y más se emancipa de las tradiciones anteriores, tanto más hipotético se hace el entendimiento y se estrecha cada vez más el conocimiento infalible.

Con la consolidación de un orden de la razón, todo parece abierto a la duda y esto implica a su vez, que no hay base evidente que pueda servir de fundamento a una práctica educativa sólida. La realidad se divorcia de la experiencia corriente, los fundamentos mismos del conocimiento humano son puestos en tela de juicio. Así, mientras más libre y autodeterminado llegue a ser el hombre, más inestables serán sus cimientos; inestabilidad y precio que se justifica pagar en aras del intuir, aunque sea provisionalmente el auténtico orden de las cosas. "Los dioses no nos develaron todas las cosas desde el comienzo; pero en el curso del tiempo, y a través de la búsqueda, los hombres descubren qué es lo mejor” (William, 1962, p. 399). 
El ascenso de un espíritu más crítico y secular, hace del hombre medida de todas las cosas. Los juicios individuales sobre cuestiones de la vida práctica cotidiana, constituye la base de principios personales y el modo de actuar personal, ya no será la tradición, ni la especulación trascendental y remota. El valor de cualquier acción está en su utilidad práctica al servicio de las necesidades de la vida concreta, individual, inserta en una sociedad, pues un hombre capaz de una participación efectiva requiere una sólida educación en diversas artes y ciencias, solo así alcanza la edad de la razón.

Esta fuerte voluntad de cientificidad no es neutral, pues la forma como se piensa la sociedad, connota múltiples variables para concebir la educación y su forma de actuar en ella. Allí donde la preocupación científica existió, institucionalizó su forma de argumentación e hizo de la pedagogía una pragmática, para producir conocimientos, para resolver problemas no necesariamente pedagógicos.

Lo característico del siglo XX hasta la década del 60 es el rechazo del camino inductivo - deductivo del pasado y la adopción del método hipotético - deductivo como método propio de la ciencia. Lo novedoso aquí está en que como no hay una lógica inductiva, no hay inducción, es decir, no hay un procedimiento riguroso para formular teorías científicas sino que se puede englobar bajo un procedimiento hipotético.

Este acto podría no tener una lógica en sentido estricto sino que pude tener muchos parámetros, tales como: aspectos psicológicos, aspectos sociales, disciplinares, es decir, todos los aspectos que puedan estar involucrados sin necesidad de contener elementos rigurosos para la formulación de una teoría. En consecuencia, el científico no recoge datos, sino que construye teoría, los datos a lo máximo producen evidencias, y en tal sentido por ejemplo para K. Popper y para R. Carnap la experimentación lo que produce es evidencia; lo que se deduce es que como tal no hay un método, pues este refiere a pasos, procedimientos, no hay una lógica, lo que interesa es una deducción. $\mathrm{O}$ en su defecto el método tiene que ver con el cómo se justifica el 
procedimiento. Esto por supuesto implica una cierta lógica, no en el acto de creación, sino en el acto de justificación. Ante la confirmación o contrastación exitosa no hay una lógica en sentido clásico, los grados de confirmación no pueden expresarse en una lógica deductiva, por lo que se requiere una especie de lógica inductiva para lo que se crea el concepto de probabilidad, no es probabilidad epistémica, ni objetiva sino que es un concepto de probabilidad condicional, pero al fin y al cabo es el único grado de confirmación de una hipótesis subjetiva dada a cierta tendencia, proporcionando cierto privilegio sobre otro. En esto está la debilidad de la lógica inductiva.

A esto va ligado el conocimiento sobre la realidad que como principio no tiene certeza absoluta sino hipotética, es falible. Al científico se le ocurren ideas, pero posee rigor cuando al descubrir una teoría nueva, ha de justificarla. La justificación exige el máximo de rigurosidad, es metódica, posee una lógica pero solo en su justificación.

El positivismo lógico, identificado a veces con el círculo de Viena, tampoco alcanzó unanimidad en el campo de la deducción, algunos hablan de que el procedimiento es verificable, mientras que para otros es apenas confirmable, falseable, refutable (Popper). Por supuesto que en orden al proceso deductivo la lógica aristotélica encuentra gran estrechez ante la lógica deductiva. Carnap habla a veces de lógica inductiva, pero como se puede deducir, tal inducción no lo es a la manera de Aristóteles o a la manera de Bacon. No es un proceso de ascenso, sino que es un proceso de deducción. Es una lógica inductiva pero que tiene que ver con la confirmación de enunciados. Carnap con su teoría del confirmacionismo, cree que la ciencia se puede confirmar, trata de construir una lógica deductiva; así, mientras uno justifica el otro refuta. El confirmacionismo parte del criterio de no posesión de la verdad, la tesis es que en cuanto a las teorías científicas solo podemos decir que pueden ser altamente probables. No se puede decir que la teoría sea verdadera, porque seguramente será sustituida por una mejor, pero sí puede ser altamente probable gracias a que ha pasado por una serie de contrastaciones exitosas; Carnap invita a seguir confirmando 
la teoría, bajo la premisa de que no hay argumentos que sean cien por ciento verdaderos, Popper más que confirmacionista es partidario de falsar la teoría, refutar la teoría, buscar dónde no se prueba la teoría.

El provisionalísimo científico implicará siempre que una teoría para que sea altamente cierta, ha de ser superada por otra teoría, en este sentido la ciencia es acumulativa, pues las teorías se van levantando unas sobre otras, es la forma como la ciencia avanza, como progresa. T. Kun dirá que la ciencia no es acumulativa sino crítica por sus nuevas propuestas.

Hoy se admite que la ciencia necesita las dos caras, el aspecto conservador (Carnap) y el espíritu innovador (Popper). Tenemos en consecuencia una argumentación desde la inducción lógica versus una argumentación desde la deducción lógica.

La filosofía anglosajona se hace heredera de estas argumentaciones de carácter cientificista que va habitando el discurso en orden a la lectura y abordaje de la realidad, mientras que la filosofía denominada continental europea, va perdiendo auge. La filosofía anglosajona, partidaria del empirismo, sustenta en mucho el positivismo lógico.

La provisionalidad de la ciencia conduce a la relatividad de la ciencia, que a su vez conduce a la posibilidad y cabida de diferentes lógicas como las de la actualidad: lógica matemática, histórica, ética, moral, etcétera. Surge espacio así a las denominadas ciencias de la discusión, entre ellas, las ciencias sociales, las humanidades. El concepto de verdad se aborda desde la relatividad, es más un concepto epistémico, más en el sentido de validez, grados de validez. El comportamiento científico además de ajustarse a una determinada lógica, se ajusta también a los fenómenos sociales, pues no es solo cuestión de argumentos, hay que ajustarse a ciertos paradigmas sociales, ciertas pragmáticas.

Aquí el humanismo y el acto educativo que nos ocupa, tiene un lugar inestable: el hombre entre objetos científicos, es decir, aquello que hay que pensar y saber del hombre: el hombre es sujeto y a la vez objeto de reflexión medio positiva, medio filosófica, es ante todo objeto teórico. 
La antropología y la pedagogía se ubican así como en un cruce de regiones epistemológicas: psicología-sociología-lenguaje, biologíaeconomía-filología. De allí surge socialmente la función y la norma, el conflicto y la regla, la significación y el sistema; surge la positividad de las ciencias humanas como campo de trabajo de varias instituciones, discursos y sujetos de saber.

Para Aristóteles la realidad queda reflejada en los pensamientos, en Kant como en los idealistas, la conciencia refleja la realidad mediante los pensamientos. Asunto bien distinto. Los pensamientos son pensamientos que poseen una conciencia más que pensamientos de una realidad. Por eso Kant habla de lógica trascendental, entendiendo trascendental como "todo conocimiento se ocupa, no tanto de los objetos, cuanto de nuestro modo de conocerlos, en tanto que tal modo ha de ser posible a priori” (Kant, A 12). Es una lógica como una disciplina que determina el origen, extensión y valor objetivo de los conocimientos, que se ocupa de las leyes del entendimiento y de la razón y solo tiene que ver con objetos a priori. La lógica trascendental depende de la estructura de la conciencia y al aplicarse a la conciencia, la lógica se convierte en una ciencia normativa. La crítica kantiana inicia así, o mejor consolida, una profunda escisión en la forma y posibilidad del conocer, con su duro ataque a la capacidad de la razón humana para trascenderse a sí misma y alcanzar lo que las cosas son, según la propuesta kantiana.

Kant (2008) se pregunta "si en efecto el sujeto es meramente receptivo en el acto de conocer”, como pretende el realismo, o si por el contrario, el conocimiento es una especie de acción, de praxis, es decir, una especie de elaboración, de producción del objeto. Según esto, el proceso del conocimiento no consiste en que el sujeto se limite a reflejar las cosas ya dadas, constituidas y organizadas independientemente de él, por el contrario, la actividad del conocimiento consiste en constituir los objetos. Para Kant lo determinante en el acto de conocer no es tanto el objeto, cuanto más bien el sujeto (Kr.r.V B XVI). Conocer es ante todo trazar el horizonte dentro del cual los objetos son objetos, es decir, construir el ámbito de la objetividad y operar desde allí. Según esto, 
conocer es ante todo elaborar las cosas para que estén en condiciones de constituir objetos. Kant enfoca el conocimiento como equiparable a elaboración, es decir, fabricación del objeto. "No es el ser quien determina a la inteligencia sino la inteligencia al ser” (García, 1975, p. 228). En esta perspectiva conviene señalar según Carpio (2004), que Kant es el antecedente de Hegel, y que sin Hegel no hubiera habido Marx, quien define al hombre no como animal teorético, epistémico, sino en función de la producción, del trabajo. La inteligencia apuntará no al ser en cuanto ser, sino al ser en cuanto objeto, en el que la inteligencia alcanza su vida propia y su gozo.

La inteligencia cambia el horizonte del ser por el horizonte del sujeto y solamente se ocupa de este bien. La falta de una episteme como contemplación de la verdad, como reguladora de la razón, conlleva una ruptura del paradigma esencial del conocer y del obrar humano. Ahora el conocer es entender lo sentido desde las categorías (Kr.r.V. B. 166 167), es la forma como la libertad humana se enfrenta con los objetos, donde el yo se impone, no desde la razón práctica de verdad y de bien sino donde el sujeto puede construir lo que quiera (Kr.r.V. A 251).

La inteligencia ha sido sustituida por la voluntad escindida de la razón. Conocer es la satisfacción de mi voluntad de poder (Bacon). No es el ser quien mueve a la voluntad, según el principio "tal es el ser tal el obrar”, donde los seres tienden a realizar su operación natural, sino que sería el objeto del deseo, pero es un deseo sin orientación específica de la verdad lo que mueve a la voluntad. La esencia del deseo es la posesión y la esencia de la posesión es la carencia, es una apropiación. En esto encuentra la sociedad de la producción y del consumo su motor y su aliciente.

Heidegger acusa a la modernidad de haber hecho del ente algo que pasa a ser un concepto genérico y unívoco, conseguido por la abstracción total de todas sus determinaciones y, por tanto, el más universal y vacío de los conceptos. Por el contrario, la abstracción formal, utilizada por Aristóteles y Santo Tomás, ha fundamentado una metafísica en la que 
el concepto ente no está vacío, sino determinado por la entidad; el ser concreto no se deduce, el conocimiento humano no puede deducir de una idea o ser supremo el ser concreto contingente y limitado, el conocimiento humano es un proceso abstractivo, no deductivo, donde los sentidos y la materia sensible son necesarios; este es un aspecto formal que, más allá de la mera conceptualización en géneros y especies, permite hablar del concepto ente como análogo y predicable de muchas maneras (Canals, 1981, p. 100).

\section{Dispersión posmoderna}

La concepción científica, refiere a características asociadas con el postulado según el cual un corpus de conocimiento o teoría tiene un estatus de episteme. Pero no todas las cosas valiosas son conmensurables en estos términos. Describe Quiceno (1998) que a finales del siglo XIX, la pedagogía entra en crisis cuando los fundamentos en los que se asentaba hasta entonces, la práctica, la observación y la inducción, sufren una inversión en su metodología acercando la pedagogía a otras ciencias y otras prácticas epistemológicas. La pedagogía mantiene su compromiso con la vida humana en su función de hallar en el hombre sus verdades, pero ahora esta búsqueda se desprende de una cierta neutralidad y en la cientificidad encuentra los modelos, como por ejemplo, los observados en las ciencias sociales, la filosofía de la historia y las ciencias del espíritu, abandonando sus clásicos fundamentos (Quiceno, 1998, p. 131). Si antes la pedagogía era la teoría y la educación la práctica, ahora la práctica se llena de teoría y la pedagogía ha de buscar sus prácticas que la legitimen y la signifiquen con sus verdades (Quiceno, 1998, p. 131).

En el marco del debate contemporáneo sobre el hecho del pluralismo, se contrasta el espíritu centralista y unificador del discurso moderno, con la defensa etnocentrista del nosotros, o de historias que se contraponen a partir de una diversidad de vocabularios (Rorty et al., 2001). Ante esto, la denominada sociedad posmoderna no se caracteriza por el influjo de una sola forma de razón dominante, sino más bien por formas 
de pensamiento y experiencia que disienten entre sí para constituir diversos lenguajes con su propia validez interna. En esta perspectiva, el conocimiento en la sociedad posmoderna ha sido despojado de sus elementos unificadores sociales, quedando solo con valores locales entre los cuales no hay modo de elegir (MacIntyre, 2001).

Esta multiplicidad de formas fragmentadas de la complejidad de la vida social y profesional moderna le presenta nuevos retos a la educación superior, tales como el mapear esta nueva etnografía, sus formas de aprendizaje, las formas de comunicación, las formas de vida y los discursos en los cuales se movilizan sus imaginarios que ejercen una profunda influencia.

En tal escenario la comunidad académica ha de tener la capacidad de mirarse de forma desinhibida, sin dejar de lado los intereses que históricamente la han concebido, como intereses necesarios en orden a su idea y función que forman parte natural de la vida académica y de las contingencias de un discurso racional.

Con E. Morín se problematiza la complejidad. Si antes la construcción de conceptos era campo de la ciencia, ahora la complejidad será una metodología, una visión, una manera de decir, un saber pensar relaciones que se pueden establecer entre el sujeto que hace ciencia, los métodos y los objetos científicos cuyo principio es el objeto y su entorno, la cosa observada y su observador (Quiceno, 1988).

A modo de conclusión parcial, tenemos que encontrar un orden en la naturaleza, ha sido un ideal clásico que puede encontrarse en Aristóteles, posteriormente el ideal de la unidad conceptual que permita sistemas racionales hasta llegar a las teorías, fue el momento de mayor manifestación del pensar científico.

Pero esta manera de argumentar en Occidente encuentra su quiebre cuando tanto Darwin como Freud advierten inconsistencias en la naturaleza que no obedecen a un supuesto equilibrio, fuerzas ocultas que 
no caen en la red de una estructura racional y menos se puedan someter a la rigurosidad de la teoría. La naturaleza puede ser perversa, aún las operaciones más identitativas de lo humano como lo espiritual, psíquico y social pueden estar marcadas por una tendencia de contradicción.

Con la complejidad, en lugar de querer pensar en "sistemas, en estructuras, en leyes y regulaciones, el acontecimiento piensa en el tiempo, en el devenir, en la irrupción, en el azar, en lo aleatorio, en lo extraño que se produce al efectuar toda operación del pensar" (Quiceno, 1998, p. 135).

Tal vez esto explica la inestabilidad del acto educativo y la tendencia del maestro a aferrarse a alguna tabla de salvación ante el encuentro con lo inesperado. La complejidad, en tanto encuentro, no puede ser entendida como el querer complicar las cosas o el querer construir cosas complicadas, la complejidad es volver a ver las cosas de otra manera (Quiceno, 1998).

\section{La educación argumentada desde la sociedad de la economía, la producción, el consumo}

En el trabajo sobre el pensar de la acción en perspectiva prudencial, Restrepo (2014) indica que la educación en la sociedad actual conduce a la consideración de la educación en un escenario donde el contexto externo está fuertemente habitado por el fenómeno de la economía globalizada, movilizada por los medios y mediaciones tecnológicas de la información, sustentada por un Estado neoliberal que presiona e influye con sus planes de desarrollo, sobre la práctica educativa, sobre todo la superior, en formas cada vez más sutiles y decisivas. Esto, por supuesto, dista mucho de aquella concepción de educación para lo superior ordenada al conocimiento y a la persona, -acciones y conocimientos-, que son ineludibles a las ideas que la sustenta.

Desde la pertinencia, no se concibe a la educación superior desatendiendo sus vínculos con el contexto externo, como lo indica Restrepo (2014), pero el escenario externo o entorno social está fuertemente influido 
de la racionalidad técnica productiva, “del mundo económico, del mercado laboral con una visión específica del talento humano, con afincamiento en los medios tecnológicos y en los términos definidos por el estamento empresarial actual” (Restrepo, 2014 p. 34). En tal sentido la actividad cognitiva es exigida hacia prácticas operacionalistas y profesionalizantes.

La idea que funda la universidad, el saber se considera como de alto nivel, como lo expresó Alaín Renaut (2008) y además que este tipo de institución se ha de ocupar no solo de aquellos asuntos relacionados con la transmisión de los saberes ya adquiridos a modo de trasnferibilidad, sino que ha de atender a su producción y sobre todo de su renovación. Las condiciones de producción del conocimiento alcanzan así una unidad de conocimientos, campos epistémicos que se consideraban como superiores. Tenemos así una forma de relación entre las representaciones epistémicas de los saberes de un lado y de otro, su organización. Pero la educación no es ni estática ni ahistórica, ella posee una línea dialéctica que permanentemente se hace sentir. La tesis de Barnett (2001) sostiene que "la idea de educación superior ha de concebirse como algo cambiante entre otras cosas a sus constantes manifestaciones de inconformidad. Por eso el proyecto de una totalización sistemática de los conocimientos implica un proceso más complejo como el que dicho saber se convierte en cultura” (p. 56), donde la transmisión de un saber de alto nivel se hace a un público más amplio como el de hoy. Que la universidad se interrogue sobre las condiciones del devenir cultural como servicio que ella bien puede prestar al saber y a la sociedad, es uno de sus compromisos irrenunciables (Renaut, 2008); sin embargo, existe un algo del quehacer educativo que se sustrae a la mera utilidad de lo social.

Esto hace que los dinamismos sociales de la actualidad, expresiones claras de los sistemas económicos globalizados e híper comunicados como es típico de la globalización, influyan decisivamente en las prácticas sociales, campo al que pertenece la práctica educativa, determinando una incidencia directa sobre la manera como se organiza 
la institucionalidad de la educación superior. Como consecuencia se configuran no solo nuevas prácticas educativas sino nuevas expresiones de vida de los agentes universitarios, porque nuevas son las formas de su relación con las personas, con los recursos, con los medios, donde no se hace extraña las concepciones funcionalistas de la educación (Durkheim, 1999).

A esto MacIntyre (1994) lo denominó como una crisis del sujeto universitario, por cuanto se producen cambios que ponen en cuestión modos de vida, actividad laboral y la relación de las personas con el conjunto del entorno económico, social y político en que viven y por supuesto en la forma como se concibe y se usa el conocimiento (MacIntyre, 1994, p. 45).

Esta crisis del sujeto universitario se extiende también a una crisis de la comunidad académica como tal, pues "no sólo como efecto de la pérdida de las autonomías como consecuencia de las políticas de Estado o del sistema económico dominante, también por los paradigmas epistemológicos incorporados en ella misma” (MacIntyre, 1994, p. 45). Esta crisis, como lo expresa Naishatat "se da entre otros factores a la ausencia de una crítica, a la difuminación de lo público ante lo privado, la importación e implantación de conceptos economicistas, la destrucción de la cooperación en pos de la competencia” (2000, p. 84). Parece así que la categoría gerencia no compagina con aquello que se identifica como comunidad cognitiva, refiriendo esta a la comunidad viva de una determinada práctica educativa.

Una de las manifestaciones de este malestar en la educación superior actual, está en la forma como se ha incorporado en ella las denominadas competencias académicas, que Barnett (2001) define como una forma de pensamiento fragmentario, un estilo cognitivo que parece conducir solo hacia competencias operativas, a una visión que desplaza la competencia o capacidad cognitivo-académica como proceso, por la competencia operativa, como producto, propia de la reingeniería y gestión económica empresarial y del mercado (p. 224). 
Restrepo (2014) señala que "tal reproducción del capital no necesita propiamente del conocimiento per se, del conocimiento como proceso de fuertes implicaciones de lo humano en su dimensión cognitiva, voluntaria y libre” (p. 38), bastaría la denominada transferibilidad propia de la empresa.

En educación, aquellos lineamientos que tradicionalmente realizaba el ámbito de las comunidades académicas, tiene hoy su escenario más en lo social, en la macro política estatal, en la empresa, en el mercado. El Estado moderno afincado en nuestra región enfrenta problemas estructurales de poder y de capacidad, como consecuencia y relación de los movimientos y sistemas que lo integran. El Estado actual es movido y en muchos aspectos le prevalece, la crisis del capitalismo tardío, que le obliga a abrirse a los mecanismos de mercado, denegando su carácter social en la atención de los ciudadanos, toca el mundo vital de los individuos -recurso humano- interviene la institucionalidad, entre ellas, la educación, intenta formas de privatización y delegación que comprometen su misión, capacidad y decisión.

La educación en general y particularmente el nivel superior, tanto por el contexto de la globalización, como por el espíritu de la sociedad de la información y del conocimiento, aparece como una institución clave de esta sociedad contemporánea. Y es precisamente por esta denominada información y cierta forma del conocimiento, por lo que se debe hablar de una educación concebida en términos más amplios en su forma y modo, distante de aquella que tradicionalmente ha forjado la denominada comunidad académica. La sociedad moderna aborda otras definiciones de conocimiento y razonamiento con nuevas nociones, nuevas formas de escucha de la realidad y de adopción de puntos de vista, habilidades analíticas, entre otras.

El conocimiento en la sociedad moderna requiere una consideración especial, aunque este se ha constituido en uno de sus rasgos identitativos. Se habla de que la sociedad es la información de la inteligencia colectiva, economía del conocimiento, sociedades del aprendizaje y de educación 
para todos a lo largo de toda la vida. Pero es necesario hacer algunas distinciones. Castells (1996) establece una distinción analítica entre las nociones de sociedad de la información y la sociedad informacional. La sociedad de la información, heredera de la sociedad industrial, refiere a la creciente capacidad tecnológica para almacenar información y movilizarla en un espectro cada vez más amplio. La sociedad del conocimiento se entiende como la apropiación selectiva y pragmática de la información. La noción de la economía del conocimiento describe a su vez aquella etapa que basada en el conocimiento sucede a aquella de la acumulación del capital físico, donde la riqueza depende cada vez más de la capacidad de la ciencia y del progreso de la tecnología. Se ha consolidado el discurso en orden a la concepción de la sociedad de la información con su par la sociedad del conocimiento (Levy, 2004).

Que el conocimiento esté fuertemente relacionado con la sociedad moderna es un fenómeno contemporáneo, y actualmente parece ser el elemento vinculante. La novedad en esta afirmación está en que históricamente ha sido la educación superior quien ineludiblemente ha estado vinculada con el conocimiento, ella ha sido la encargada de su producción y comprensión por la investigación, como la adquisición y transmisión por la enseñanza y otro tanto en ser la salvaguarda de dicho bien. Pero así como puede llamar la atención que la sociedad actual esté tan interesada en el conocimiento, sobre todo el mercado global, empresarial y gerencial de las patentes, la tecnología y las comunicaciones, de la misma manera llama la atención que la educación superior se vea concebida y volcada en toda clase de negocios, como la preparación de mano de obra, el talento humano, la gestión de proyectos, el negocio del conocimiento, de la investigación como factor de lucro y mercado. Sin embargo, un hecho es claro: en las formas de conocimiento que busca la sociedad contemporánea y aquellas que históricamente ha de buscar la universidad se da un movimiento dialéctico. El conocimiento que promueve la sociedad actual, se identifica con un interés y formas del conocimiento heterogéneo, distinto al que se puede encontrar originalmente en la educación superior. 
John Stuart Mill, en su obra The Spirit of the Age (El espíritu de la época) (1831) sostiene que el progreso en la mejora de las condiciones sociales no son resultado de un aumento de sapiencia o de la realización colectiva de la ciencia. Estaría, más bien, relacionada a la difusión generalizada del conocimiento, unido al incremento de elección del individuo, tal como lo proclama Amartia Sen (2010), es decir, una emancipación de las libertades resultaría en una más amplia difusión del conocimiento y la educación, aspecto que tiene buena acogida en la noción de la sociedad actual.

Una distinción simplista nos dirá que el conocimiento son todos aquellos elementos del proceso por el cual la mente humana comprende y se hace a su entorno y por su parte la información responde a aquellos elementos que en la cultura actual obedecen principalmente a intereses económicos y comerciales.

Pero esto no significa que tal relación se dé en una forma desprovista de cargas o fuerzas, lo que hace pensar que no es una relación rectilínea, como aquella según la cual, la educación en tanto gestora del conocimiento por la investigación, configura la sociedad o el Estado, o que la educación superior con su específica manera de gestionar el conocimiento y las epistemologías en las que lo produce, se traslapen a la sociedad a modo de irradiación; sin embargo, en cuanto al conocimiento se da una relación triangular dinámica y dialéctica generando movimientos bidireccionales, pues cuando la sociedad absorbe a los profesionales graduados, ya no lo hace en el sentido de un acople de estos según la mirada de la educación superior, ahora es la sociedad y la empresa, quien emite señales o marca pautas respecto a cuáles son las capacidades cognitivas que requiere, cual la cualificación que ha de tener el profesional, cual ha de ser su perfil técnico operativo.

La sociedad muestra favoritismo hacia aquellas formas de conocimiento que tienen un claro valor en el mercado de trabajo. Esto hace que se establezca un interés por aquellas formas de conocimiento que se pueden describir como operacionales, técnicas, computacionales o de 
pensamiento estratégico, es decir, relativas a la tecnología, la matemática o la informática, también aquellas que ayudan a la contabilidad, el planteamiento de problemas y a la administración. Esta tendencia por supuesto es una visión univocista del conocimiento.

Como producto, el conocimiento se considera un bien que da valor a aquellos que en la educación superior obtienen las últimas competencias, las vigentes, las que marca el mercado. Pero visto así el proceso, la educación superior, ya no sería ese espacio genuino que se considera valioso por sí mismo, por las implicaciones que tiene para el universo personal. La capacidad concebida como competencia operativa ya no es una cualidad intrínseca del desarrollo connatural de lo humano, como despliegue de las capacidades de sí mismo, sino como producto.

El conocimiento recibe así un tratamiento que lo convierte en idea técnica que lo conduce a la unidimensionalidad en diferentes formas. Beuchot (2011, p. 147) plantea que la vida intelectual en general, y la educación superior "refuerzan la unidimensionalidad de pensamiento y de la acción, característica del capitalismo tardío”. El saber pedagógico ya no será de carácter epistemológico, sino de carácter metodológico, como ciencia que estudia las técnicas educativas (Martínez, 2002), prima la enseñabilidad a la educación misma. Algunos modelos pedagógicos movilizan concepciones en orden a adoptar términos del mundo de la producción, del lenguaje de la cualificación profesional, la eficacia de los procesos docentes, categorías que pueden esconder prácticas en orden a planteamientos instrumentales de la educación, a procesos de formación cargando de presupuestos técnicos la enseñanza.

Las capacidades operacionales queprivilegia la sociedad contemporánea, promueve un modo de ser de la educación superior que gesta y configura a las personas y las formas de conocimiento de un modo limitado y específico, que producen un cierto prototipo de sujeto, el que se requiere y ajusta a las condiciones de la sociedad. 
Según Jacques Derrida (2001), citado por G. Hoyos (2002) “La universidad se comporta con respecto al poder como con un extraño (...) la verdadera universidad debería ser un lugar donde lo impredecible pudiera volverse acontecimiento”.

La sociedad moderna se caracteriza por la capacidad de generar y trasmitir conocimientos, especialmente técnicos, fuera del campo académico tradicionalmente identificado. La educación sobre todo la superior, ya no posee ese ethos que le es propio, valioso en sí mismo. La capacidad concebida como competencia ya no es una cualidad intrínseca del desarrollo connatural de lo humano, es fácilmente equiparable a emulación o adiestramiento. El conocimiento recibe así, un tratamiento que lo convierte en una idea técnica que lo conduce a la unidimensionalidad. El campo de las disciplinas movilizadas en los currículos de educación superior se constituye en campos propios de formas de reduccionismos.

A medida que la comunicación digitalizada, electrónica, virtualizada va tomando amplio espectro, sucede tanto al conocimiento, como a la educación superior que lo moviliza, una transformación en la que puede suceder una conversión del mensaje por el medio, ya que se puede convertir el medio en el mensaje mismo, al tomar tanta relevancia, como lo advertía McLuhan (1994, p. 95) “a partir del proceso de evolución de las técnicas de producción y de las fuerzas productivas, los medios sustituyen en importancia a los mensajes”. El universo conceptual se torna homogéneo y la industria educativa simplemente acompaña este proceso.

Así como el conocimiento y la información, también la tarea de investigar ha llegado a convertirse en elemento clave de la educación superior, y pareciera que es su elemento diferenciador. Sin embargo, no siempre ha sido así, más bien tal vinculación es contingente, condicional e incierta. Wittrock (1991) describe ampliamente los orígenes de la universidad investigadora y cree que la universidad tal como la conocemos hoy, ha 
estado más referenciada con los momentos políticos propios de cada época y con el desarrollo económico y social, que con la investigación misma y otro tanto, la investigación ha sido más factor de obtención de recursos y reconocimiento que de generación de conocimiento.

La investigación en la educación superior manifiesta más que amor al saber, amor al dinero de la patente, y esto puede ser la causa de la disolución de la universidad, dada la extensión y globalidad de los sistemas y su alto grado de influencia Hutchins (1959, p. 30). Se toma como pretexto que la investigación sea más importante que la docencia misma, se investiga aquello que en el mundo de la oferta y la demanda tiene interés, y no tanto por los fines mismos de la educación que son el conocimiento, el cultivo de la conciencia, el cultivo de la razón. La obra Sin fines de lucro de Nussbaum también denuncia este fenómeno.

A modo de conclusión: La profesionalización es una tarea importante de la universidad, pero no la esencial. Profesionales pueden adiestrarse incluso en instituciones que no tengan las características de educación superior, pero la tarea fundamental de la universidad es formar personas en el conocer y en el actuar, como buenos ciudadanos, críticos, independientes, con conciencia clara y con decisión ante las responsabilidades. Esto es parte de la misión esencial de la universidad. En la perspectiva de una sociedad establecida en orden a las necesidades del mercado libre, esta misión de la universidad no es propiamente retributiva.

La educación superior en esa sintonía con la sociedad económica, tiende a su vez a configurar la acción de los maestros según una apuesta por lo pragmático, que puede resultar incompatible, puede reñir con lo que implica la idea y los fines de la universidad. Para poder hacer docencia de una buena clase, para poder hacer investigación de primer orden, se necesita comunidades cognitivas con condiciones distintas al maestro exigido por la sociedad de consumo. 
Las transformaciones sufridas por la academia en su trabajo cognitivo devienen en una masificación de la universidad y surge también una nueva figura de intelectual de masas que revalúa la figura del maestro en una intelectualidad difusa, una clase que se aproxima a una pseudoproletaria del trabajo intelectual (Virno, 2003).

Con el cambio de concepción de educación superior marginal y elitista a masiva, el cuerpo docente ha visto reducidas las formas de producción intelectual, Ahora se trata de un oficio no un arte. La comunidad académica agencia para otra instancia. El oficio ya no es tomado por decisión propia, ni pertenece a los actores, pese a que han invertido allí gran parte de su identidad personal y social. El trabajo académico cada vez está más especificado y generalmente está plegado a planes y programas externos al maestro mismo, con lo cual el campo en el que el académico puede maniobrar se va estrechando en lo cotidiano.

La enseñabilidad vincula un sinnúmero de profesionales disciplinares sin conocimiento del que y del a quien educar y menos formar, con la consiguiente disminución del ethos educativo. Un cuerpo estudiantil más amplio, mediciones de tiempo concebidos más para la empresa que para la academia y sus proyectos, la versatilidad de la comunidad académica con la incorporación de numerosos profesionales, no educadores, más inspecciones de las actividades de vigilancia y control, ampliación de las tareas que los docentes han de realizar, son un buen conjunto de aquel malestar en la vida académica, causas de malestares del sistema.

La denominada proletarización que aquí se aplica por supuesto por analogía, plantea el problema del profesionalismo en la actividad académica. Parece que la condición de profesional es inadecuada para la comunidad académica. Los profesionales son personas calificadas, que realizan un trabajo por el cual reciben remuneración, como fruto de la prestación de un servicio a unos clientes. La comunidad académica, en una buena proporción, cuentan con los ingresos que le aporta el presupuesto del Estado, y otro tanto hacen en la entidad privada. 
Por esta razón, el carácter y la calidad del servicio prestado en las condiciones actuales no denota diferencia con quien realiza un oficio. Las agremiaciones académicas levantan sus voces ante las reformas que frecuentemente pretenden desmontar aquello que queda de estabilidad y amor al trabajo, sin las urgencias por los estándares, reformas que pretenden que los académicos tengan que demostrar su profesionalismo, ser explícitos respecto a la naturaleza de sus actividades y estar dispuestos a ser calificados. A este cierto tipo de proletario académico, Franco Berandi (2003) lo denomina el cognitariado, así como en el pasado en las relaciones de trabajo se hablaba del proletariado en categorías de Marx y Engels, el cognitariado resulta ser ese nuevo sujeto estratificado en el régimen inmaterial de la producción del conocimiento.

Las nuevas condiciones laborales de los maestros, la incorporación de los profesionales al estamento educativo, conlleva el problema de no contar con una idea clara de maestro profesional que dé cuenta de su papel en la vida académica. Kant, con su trabajo sobre la pedagogía, pensó que los profesionales son aquellos que profesan una ciencia y dado que su propuesta fue ordenar la educación con la idea de la ciencia, no a la de la práctica, como se había realizado desde tiempos inmemoriales, repercutió en posteriores desarrollos que conllevó pensar al profesor profesional como aquel que posee un conjunto de conocimientos que sus clientes no poseen.

La relación profesional - cliente, se basa según las ciencias de la administración, en la confianza (Giddens, 1997). Así que, el comprador espera que el profesional entregue sus conocimientos a favor de los intereses del cliente. Esto tiene su lugar en la sociedad de la oferta y la demanda, pero en el escenario de la educación superior ha de ser distinto.

Una concepción de educación superior desde esta perspectiva, conlleva la idea de estudiante como producto que aporta connotaciones de finalidades predeterminadas, calculadas, de resultados uniformes y de un proceso durante el cual, a través de la aplicación de algunas técnicas, 
los estudiantes alcanzan unas competencias. El estudiante sufre una transformación pero es distinta a aquella transformación que ocurre en él por el proceso del conocimiento y como fruto de un proceso de formación. El estudiante es literalmente el producto, consecuencia del impacto de las estrategias aplicadas. Pero esta visión no parece definir suficientemente lo que es un proceso de formación en lo superior, en la cual se habla de incidencia, pues siempre implica alguna respuesta activa por parte del estudiante que debe realizar una interiorización y un intercambio dinámico hasta que se apropia de los pensamientos y configura la acción.

En el tratamiento de las relaciones educación superior y conocimiento, el estudiante y el profesor como parte de aquella categoría sujeto universitario, ve desplazamientos que implican redefinir los roles de los actores universitarios en los cuales el docente de auxiliador, según el estadio y etapa de desarrollo humano del estudiante, pasa a agente instructor - observador y por su parte el estudiante de actor activo, capaz de generar preguntas y arriesgar respuestas, pasa a ser receptor de competencias emulativas o transferibles propias de la instrucción, que se alcanzan con la aplicación de un conjunto de técnicas que aseguren que el estudiante presente ciertos resultados garantizados y uniformemente medibles con pruebas nacionales y regionales.

La concepción de estudiante como producto, pretende unificación, univocidad, como tendencia favorable a un mercado que evita la dispersión del cliente con la uniformidad cultural y social y la predictibilidad de las tendencias para una mejor planeación de la naturaleza de los recursos con que contarán, entre las que se incluyen la fuerza de trabajo que ofrecen los egresados.

Lo superior implica una transacción genuina que ha de desarrollar el estudiante en su proceso de aprendizaje y esto implica el manejo de las teorías de la enseñanza que la categoría de profesional no incluye necesariamente. 
El académico, inserto y convalidado en una comunidad académica, se ocupa del conocimiento como tal, y el conocimiento se encuadra en un campo epistemológico específico, incluido dentro del territorio general del conocimiento formalizado. El académico profesional también tiene su propia área de intereses cognitivos gremiales, la diferencia con la comunidad académica en sentido estricto estaría en que las profesiones o ciertos profesionales se ocupan de la utilidad pragmática de los conocimientos que la comunidad cognitiva produce, dejando que el académico se interese en la veracidad, solidez, creatividad de las ideas, independientemente de cual sea o pueda ser el interés en las aplicaciones de las mismas.

Los académico tienen en el conocimiento un interés particularmente fuerte, pero de cara a la sociedad es un iteres que se va dando dialécticamente. El académico tiene una responsabilidad en su rol con la sociedad, frente a ciertas formas de conocimiento que se van tornando dominantes en la sociedad moderna.

Tanto Horkheimer y Adorno (1999) denuncian el olvido de la responsabilidad ética colectiva y el olvido de la comunicación generosa y directa como consecuencia de la aparición avasalladora de la racionalidad técnica instrumental y el empobrecimiento racional de la sociedad. La sociedad ciertamente es hoy más letrada pero se trata de un conocimiento tal vez más empobrecido. No es la universidad la que determina la naturaleza del conocimiento, ni cuáles son los conocimientos substanciales. El conocimiento como concepto, es un bien social, reformulado continuamente en respuesta a los cambios, a las circunstancias sociales y al ritmo de las comunidades tecnológicas.

\section{Implicaciones pedagógicas}

Las connotaciones del contexto contemporáneo conducen a un camino ambivalente en el interior de las propuestas académicas en nivel superior. Alvira (1980) expresa que la teoría educativa hoy es una teoría del saber hecho arte, en la cual el querer se identifica como ejercicio de dominio, 
de poder como lo sugiere Bacon. Así el acto académico entendido bajo variables cuantitativas, se interpreta como producto. El teorizador es un fabricador, como se puede deducir de las teorías kantianas. Así el saber se instrumentaliza, la teoría epistémica dejó de ser teoría práctica, pasó a ser teoría técnica, y esta última reduce el operar humano al producir.

Privar al hombre de la posibilidad de su capacidad de verdad objetiva, de moralidad objetiva, de libertad objetiva, es su peor mal (Segura, 1994, p. 576). Para Arendt (2008, p. 128) “en ese proceso, tanto el conocimiento como la acción humana se empobrecen y se achican. El conocimiento se convierte en simple información y la acción, en simple trabajo”. Allí la acción educativa, queda igualmente comprometida, subsumido en un voluntarismo sin salida a la condición humana. Además se pierde o se reduce la visión de las acciones humanas, como un asunto complejo y se reducen a un solo aspecto del despliegue de la acción: al producto mismo, en términos de Arendt (2008), que en el caso de la educación es el resultado, la medición, la acreditación, el ranquin.

Se entiende al hombre no como una totalidad sino como objeto científico, como fenómeno observable, como una concepción científica. Se incorporan desarrollos de estudios de la psicología experimental al currículo, se estudia al niño en su evolución mental para adaptar a él la pedagogía como lo hace el Instituto J. J. Rousseau en 1912 en Ginebra. Otro tanto hace J. Piaget. Aparece la infancia como objeto del proceso educativo, la psicología será la ciencia base en vez de la filosofía de la educación o la enseñanza ético-moral.

Estas incorporaciones implican grandes modificaciones prácticas para la vida de los maestros y como consecuencia es urgente preparar maestros, pues más que el maestro mismo, urge asegurar el progreso y desarrollo de las ciencias de la educación. Esto conduce a una pedagogía experimental y a una psicología evolutiva para lo que es necesario recurrir a un discurso especulativo apoyado en la filosofía de los porque, y del cómo educar. Es una nueva psicología ligada a las ciencias de la vida. Es el paso de la psicología racional a la científica, 
de la práctica a la teoría. Se consolidan los saberes modernos como las pedagogías descriptivas, no normativas, no ordenadoras de la vida humana.

La filosofía de la educación superior, en su campo de estudio, ha pasado de explicar y ordenar el quehacer educativo formativo a arbitrar la considerable manifestación de ciencias fenoménicas, dado que no es posible encontrar una esencia común. M. Heidegger (2003) hace un penetrante análisis, al indicar que la dispersión de la investigación en tantas especialidades, va contra aquel ideal clásico de hombre sabio, en pro de un hombre productor, hábil, con excelentes rendimientos. En ese mismo sentido Carlos Cardona (1973, p. 13) identifica la voluntad de poder como la causa última de la diversificación pedagógica actual. El educar se torna una reflexión no antropológica sino sociológica. Como comenta Llano (1983, p. 115): "la realidad concreta del hombre, se dispersa en las estructuras epistemológicas de las diversas especialidades; lo humano queda objetivado en función de miradas parciales. Por ello mismo, el saber aparece como deshumanizador”.

De esta manera, la técnica, el obrar racional y el comprender, pierden su jerarquía, pierden su thelos al reducirse a un engranaje de conocer - producir. La episteme se torna producción y desde allí se fragua un criterio de verdad. En este marco de teoría se identifica fácilmente el saber con la capacidad de previsión y de dominio, se rompe con la apertura amorosa a la realidad, fuente de toda objetividad y perfección, rompe con el asombro que caracteriza la actitud filosófica clásica, o teoría contemplativa como amor a la sabiduría. El saber moderno convierte al hombre en “dueño y poseedor de la naturaleza” (Llano, 1981, p. 325).

Mientras los antiguos toman como punto de partida el "saber cómo se puede vivir en conformidad con el orden dictado por la naturaleza" como lo indagaron los presocráticos, ahora se parte del planteamiento del dominio técnico de la naturaleza. Del escenario educativo partícipe 
de esta cosmovisión, puede surgir un hombre "racionalizado" o “ilustrado” que es, en palabras de Mardones (1988, p. 31), un tipo de hombre orientado al dominio del mundo con una mentalidad funcional y unas motivaciones morales autónomas, en una sociedad económica y burocrática, un ámbito que va moldeando estilos y formas de vida, alimentadas muchas de las veces desde lo educativo.

Mientras la idea pre-moderna de educación va a la estructura escolar y a una práctica, la modernidad idealista va a la idea, la educación se concibe como una idea, como un concepto, no como un espacio. Kant abstrae lo real, y crea el concepto. En tal sentido el hombre es un concepto de libertad, de moral, de cuerpo, de espíritu, un sujeto empírico, un sujeto trascendental. Es un experto que conecta medios y fines de manera valorativamente neutral, agente moral, alguien que no esté disminuido, es decir que alcance la mayoría de edad (Kant, 2003) que sea aquel ciudadano ideal (Rousseau, 2000). Prontamente el pensamiento dominante de la modernidad idealista, desacralizada y laicista, se integró con una forma de pensar de tipo racional y positivista, situando en el centro de este universo, la figura del ciudadano libre e igualitario.

El concepto habla de lo real en forma abstracta y esto es ciencia que se limita a un espacio y a un tiempo. Así como el pensar precede al conocer, la idea a la realidad, en tal sentido el saber precede a la actuación pedagógica y como tal es un saber teórico, que se puede prever, anticipar al error, es un saber antes de que suceda porque se puede controlar. El pensador, el científico, ha de ser el pedagogo antes que ser un doctrinero. La industrialización traería los propósitos de la económica social y productiva como antesala de la economía del conocimiento virtualizada de la actualidad.

Como tal, cada idea que sustente una determinada práctica educativa, sostiene, genera o crea un determinado sujeto y una determinada episteme para esa concepción. Aquella visión desacralizada hace de 
la educación una pedagogía del saber científico conceptual teórico (Kant, 2003), donde el objeto y el sujeto son abordados como objetos y realidades múltiples, da cabida a un actor distinto, al docente de la ciencia, un tercero que reemplaza al maestro, para llegar al profesor como el que profesa una de muchas ciencia particulares, donde la persona y la educación son afrontados como objeto desde una visión pragmatista, funcional social e interdisciplinaria (Durkheim, 1975) hasta llegar al profesional tutor de las tecnologías curriculares aplicadas a la educación para resolver necesidades, para transformar la realidad, para intervenirla con la experiencia (Dewey, 1975).

Los directivos, los profesores, los estudiantes no solo son personas con intereses particulares, sino también grupos que, aunque se encuentren frecuentemente fragmentados, tienen sus propias apuestas e intereses. Son actores sociales que llevan adelante proyectos e intenciones particulares y colectivas. Una concepción que permita comprender, que las prácticas sociales se insertan en un marco social más amplio, admite que estas prácticas no son inamovibles, que concurren con cambiantes ideas sobre las formas como las personas y los grupos interactúan.

Al fondo del debate, se asoma una sociedad para quien "la transferibilidad de la productividad, la búsqueda de fuentes de riqueza y de empresa es lineamiento para la educación superior” (Barnett, 2001, p. 125), lo cual es en cierta forma plausible, pero tal propósito no siempre va emparejado con el desarrollo de los factores connaturales de la persona, por cuanto estos implican del acto educativo un modo de ser más allá al de la mera transferibilidad, implica un ethos más ajustado a lo humano a la educación superior y para lo superior.

La enseñanza práctica en la educación superior, presenta una compleja problemática ética, dada en la insuficiencia y fragmentación de la vida humana en compartimentos o estancos -disciplinas-, cada una con su lógica y su normatividad -deontología- particular (MacIntyre, 2004 p. 24). La Unesco advertía acertadamente que sin una adecuada formación para el actuar -ético- el dominio de la técnica y de las poderosas 
herramientas productivas se convierte en un potente instrumento de la voluntad de poder de los grandes grupos económicos (Hallak y Poisson, 2007).

Aquellas ciencias que se ocupan del hecho educativo como fenómeno social, económico etcétera, hace de la pedagogía una ciencia descriptiva no normativa. Pero siendo rigurosos con el objeto de la pedagogía, Martínez (2004) indica que esta pertenece al ámbito de lo práctico, de lo agible.

La disciplina o disciplinas que se interesen por la educación en cuanto tal serán, pues, ciencias prácticas y no especulativas; es decir, no sólo investigarán qué sea la educación sino que han de pretender que la educación lleve a efecto. Toda ciencia práctica es un saber ordenado a la acción y tiene como acto propio un conocimiento de dicho orden por sus causas; el saber práctico particular está ordenado a una acción concreta a realizar de ahí que sea práctico-práctico (2004, p. 31).

Tomás de Aquino identificó que el mejor conocimiento práctico es el más cercano a la acción, esto es, a lo particular (S. Th. I. q. 22, a 3 ad 1). Al ser práctico este saber acerca de la educación, y en base a atender al fin de educar, es precisamente este fin el que constituirá el objeto formal de ésta práctica. El papel de la educación en este sentido es esencial y ha de hacerse sentada en la verdadera naturaleza del hombre. A ello se aplica la estructura básica presentada por Aristóteles y Tomás de Aquino en la cual se da un contraste entre el hombre tal como es, y entre el hombre tal como podría ser, si realizara su naturaleza esencial, según lo abordan en la Ética a Nicómaco y su Comentario. Esta transición es posible por la ética y la acción práctica, y ambos presuponen la esencia del hombre como ser racional y una interpretación del thelos humano. Por su parte los preceptos que ordenan los deseos y emociones por las virtudes y prohíben sus vicios, instruyen acerca de cómo pasar de la potencia al acto, de cómo realizar nuestra verdadera naturaleza y alcanzar el fin (St. I-II q., 57 a 5 in c). 


\section{Por una pedagogía sensata}

Según Martínez (2002) al definir la educación por su género, nos encontramos con aquello que la filosofía denomina la teoría de las causas que es todo lo que determina al ente en una especie por lo que afirmamos de este que es acto. En el capítulo segundo, del libro quinto de la Metaphysica, Aristóteles expone su consideración de las causas, como alternativa para declarar ese "primer principio ante el cambio y la quietud” (Aristóteles, Metaphysica, V, 2, 1013a 33). En efecto en la búsqueda de la causa absoluta de las acciones, parece que la realidad misma se resiste a ser explicada mediante la contestación a una sola mirada, que en la expresión aristotélica es al menos pentaédrica su conocimiento puede accederse contestando a las cinco preguntas que indagan por sus cinco causas: Si preguntamos qué es, contestaremos con su causa formal, si preguntamos de qué está hecha, contestaremos con su causa material, si preguntamos cómo se hace, contestaremos con su causa ejemplar, si preguntamos por qué es, contestaremos con su causa eficiente y finalmente si preguntamos para qué es, contestaremos con su causa final.

Afirma Tomás de Aquino, que "la definición perfecta de cada cosa se hace teniendo en cuenta todas sus causas” (S.Th. I-II q. 55, a.4 in c). Después de la aparición de la ciencia en términos modernos, es de entender que el concepto de cusa, ya no designa como designaba para Tomás y Aristóteles un conocimiento. Ahora la ciencia es analíticoempírica y se define ante todo por un método e implica siempre el criterio de comprobación.

Independientemente de la aceptación o no de este criterio aristotélico, cada momento del desarrollo histórico del pensamiento ha hecho énfasis en una determinada causa. Así el Renacimiento despertó el interés por la noción de causa final, en la época moderna se fue imponiendo cada vez más la noción de causa eficiente; además, se impuso la noción de una causa que, en vez de dar razón de las cosas mismas, da razón de 
variaciones del estado y desplazamientos en el espacio de acuerdo con leyes expresables matemáticamente.

En el Comentario a la Ética a Nicómaco, Libro II, Lección II n. 160 dice Tomás que en las ciencias especulativas, en las que se busaca solo el conocimiento de la verdad, es suficiente con conocer cuál es la causa del tal efecto. Pero en las ciencias operativas, cuyo fin es la operación, es necesario conocer por cuáles movimientos u operaciones tal efecto sigue a tal causa.

En la denominada recuperación de la teoría de la acción Elizabeth Anscombe destaca por el de haber dado nuevos bríos a los estudios sobre la acción humana y la racionalidad práctica, con su libro Intención, aparecido en 1957 para distinguir la “intención” de las “causas mentales". Anscombe en el parágrafo 1 de su obra, distingue tres sentidos de intención: “acción intencional”, "intención con la que” y "expresión de intención”. Es un hacer justicia a un conocer que no consiste en la adecuación a unos hechos anteriores a él-empirismo-, sino precisamente en ser causa de lo que se conoce. Se trata "simplemente" de aquello que convierte una serie de sucesos del mundo en una acción humana (Anscombe, Intention, 19).

La causa formal contiene una doble relación: respecto al ente, es el principio que lo específica y determina; respecto a la materia, es aquello por lo que ésta se actualiza. Por la causa eficiente son actualizadas las diversas potencialidades de la materia. La causa eficiente y la causa final que en sí poseen diferencia específica en la acción de educar coinciden, aunque en otro sentido con la causa material. Por su parte la causa ejemplar, modelo que imita el artífice, tiene con respecto a la acción educativa, razón de causa final, por lo que puede quedar reducida a esta (Martínez, 2002, pp. 141-142). En esta materia, es indispensable atender a aquello que $\mathrm{C}$. Llano afirma de no subsumir la causa ejemplar en la causa eficiente o en la causa final, aspecto que se ha de aclarar con la precisión en las relaciones entre las causas. 
El sujeto, pude considerarse la causa material de toda acción, y por consiguiente de la educativa; mas no por ello deja de ser, en otro sentido, principio activo, es decir, principio formal de la acción. "la actualidad se encuentra primero en la forma sustancial antes que en su sujeto. ...A su vez resulta que la actualidad de la forma accidental es causada por la actualidad del sujeto. De este modo, el sujeto, en cuanto que está en potencia, recibe la forma accidental. En cuanto que está en acto, la produce” (S.Th. I.q.77 a. 6 in c). El sujeto produce o actúa “en cuanto está en acto". Este es el fundamento, de la causalidad eficiente. La producción del efecto significa que éste pasa de la potencia al acto, pero una forma en potencia "no se llevaría a sí misma de la potencia al acto” por lo que se requiere algo en acto que desde su perfectividad actualice dicha forma, haciéndola pasar de la potencia al acto; y ese algo en acto es la causa eficiente.

Un ente es creado cuando pasa del no-ser al ser, y en las coordenadas de Tomás de Aquino, solo Dios puede hacerlo. El efecto que se produce es el ser creado. Pero el efecto que se produce puede ser también educido, cuando la forma está en potencia en algún sujeto ya existente, del cual se saca (educere). Así, si la educción es sustancial se habla de una generación o si es una forma accidental, se habla de una alteración. "Si la causa eficiente sea un sujeto y el efecto se da en otro distinto, como es el caso de la acción transeúnte que (...) va desde el agente hasta la cosa exterior, a la que transforma, como el iluminar" (De Veritate q.8, a.6 in c).

Las acciones inmanentes exigen, por el contrario, que el efecto se dé en el mismo sujeto que es su causa. De esta forma, cuando alguien entiende algo lo dice en su interior; este decir es causado por el mismo sujeto y su efecto es el verbum mentís o palabra mental. No es que la forma en potencia haya pasado al acto por su propia virtud, sino que deben diferenciarse en el mismo sujeto algo en acto y algo en potencia: en acto está el entendimiento agente, que es quien hace inteligible la forma que estaba en potencia de ser entendida, pasando entonces el 
entendimiento en potencia a acto de entender, formando la palabra en la que dice lo conocido.

El sujeto que se educa es la causa eficiente de la educación y esto implica analizar entonces qué tipo de agente es según se dijo. Si la educción es sustancial se habla de una especie de generación o si es una forma accidental, se habla de una alteración. El asunto importante es si la acción que implica el educere es una causa creadora o eductiva, si causa generación o alteración, si es un sujeto distinto o el mismo educando. Aquí parece estar el punto fuerte del análisis del concepto de formación en la perspectiva de Tomás de Aquino, quien precisamente utiliza para la definición de educación con frecuencia el concepto de educere.

Un análisis etimológico de la mano de A. Ernout y A. Meillet (1979) indica que el verbo educar nos acerca a uno de sus primigenios y real significados. Nace del latín educare, conducir, duco y ex que indica procedencia, significando el compuesto extraer, conducir hacia fuera y hacia arriba, elevando. Educe -imperativo de educo, educere sacar de, extraer. Es un proceso que tiene una dinámica que debe conducir a excitar desde adentro del individuo toda virtualidad y posibilidad que como persona posee en estado germinal y que debe sacar a flote para su proceso de realización personal y elevarse así a la plenitud de su ser (Ernout, 1979, pp. 186, 192, 204).

Desconocer el proceso de la causa eficiente de la educación puede tener graves consecuencias, especialmente las que se derivan de quien ejerza dicha causalidad; así, un maestro o un gobernante que sustituya a los padres en la educación de los hijos; un educando que asuma la dirección de su propia formación dejando al maestro como mero supervisor; un educador que determine a su discípulo sin contar en modo alguno con la iniciativa de este; un maestro que abandone toda la virtud educativa en las técnicas, son claros ejemplos de una inadecuada comprensión de la causa eficiente en educación. 
En definitiva, un educador desdibujado, indefinido pierde su capacidad de actuar sobre el educando, disipándose su perfectividad; el agente que lo sustituya no lo hará entonces desde la educabilidad, sino desde cualesquiera otras razones o técnicas o mera enseñabilidad, o el imperio del método, que no se ocupa explícitamente o en primera instancia de la idea de formar al hombre. La entrada de la actividad educativa al discurso propio del conocimiento práctico implica como lo afirma Bárcena (1991, p. 233) "un mayor protagonismo reflexivo del educador en su trabajo, lo cual significa, además, tener, que admitir que la práctica educativa no es una mera cuestión técnico instrumental, sino una forma de praxis dirigida y decidida deliberativa y éticamente".

En consecuencia, la idea o modelo rector de tal cambio, aunque pensados por otro, deben ser queridos o aceptados por quien ha de sujetarse a ellos haciéndolos propios. En cambio cuando se trata de la materia sobre la que trabaja el artífice, la docilidad o rebeldía de esta materia no son más que transposiciones antropomórficas que ocultan un mayor conocimiento o desconocimiento de las leyes físicas subyacentes respecto a esa materia por parte de quien quiere transformarla.

En las transformaciones humanas, no basta el conocimiento de las leyes del hombre, porque este, además de ellas, cuenta con la propia libertad de quien quiere transformarse a sí mismo. Esto desencadena una importante consecuencia para aquellas actividades cuyo término de transformación no son los objetos -como ocurre en las técnicas y en las artes usuales- sino los sujetos humanos. Esta actividad transformadora, en cuanto que es extra-subjetiva respecto del transformador, en cuanto que, cabe decir, transforma otro sujeto, puede considerarse por supuesto como poiética. Pero en cuanto que lo transformado es, a su vez, sujeto, aunque sea otro sujeto distinto del transformador, pertenece, por igual, al modo de la acción práctica.

En Tomás de Aquino se encuentran las dos concepciones de educación tanto como arte, y como praxis. La dirección de organizaciones, la educación, la conducción de grupos humanos, el gobierno de la 
comunidad social, etcétera, enfrentan aquí de continuo una opción fundamental, de la que depende todo el proceso transformador.

Algunas expresiones del existencialismo sobrevaloran el aspecto de la libertad personal. La sociedad en los términos en que actualmente se define y determina, connota para la persona, en muchos aspectos, cosificación u objetivación de la persona misma que se produce por ejemplo en el ejercicio profesional hoy cuando erróneamente se quieren ejercer sólo de acuerdo con las leyes de la técnica, cuyo objeto no es lo persona, sino la cosa (Millán-Puelles, 1958).

Muchas expresiones de las lógicas de mercado, la cultura del consumo y la razón técnica instrumental, terminan imponiendo al sistema educativo y prácticamente en todos los estamentos sociales, una acción conceptualizada bajo la óptica de las ciencias positivas, como técnica transformadora apropiada para objetos, no propiamente para la condición de la persona. Y esto, no como una equivocación accidental, sino como fruto endógeno que brota de su concepto del hombre en cuanto ser condicionado por las relaciones de producción y de consumo. En este sentido, es posible en un materialismo una estrategia conductista, pues el hombre no es susceptible de transformaciones voluntarias internas personales, sino que cambia con la modificación de las estructuras sociales que evolucionan determinísticamente, como se pensaba en el marxismo.

La realidad es que toda modificación respecto de un sujeto, intentada o pretendida por otro, debe ser una llamada a la automodificación de aquel. Si no es así, el cambio será periférico y superficial, y entonces tal vez tenga, que recibir el calificativo de solo poiético en su sentido más técnico. En tal caso, no se pretenden cambios profundos en la sociedad, cuando se implican sólo cambios epidérmicos en las personas. Cabe recordar que la reflexión subjetiva personal que todo individuo ha de llevar a cabo para transformarse a sí mismo, no se sustituye por el análisis objetivo aplicable a la materia que se pretende transformar mediante la acción poiética. Aquella reflexión en la praxis 
es un momento intelectual clave en toda acción, y la sustitución de la reflexión práctica por el análisis poiético representa una nota diferencial entre la praxis y la poiésis. Esto es en definitiva el cambio de dirección que se quiere plantear para reconfigurar aspectos que la formación para la acción prudencial en educación superior requiere actualmente.

\section{Conclusiones}

Ante la pregunta ¿cómo ha de vivir el hombre plenamente? ha tenido que ver la educación y se ha dado históricamente en una doble vía: el bien de la persona es intrínseco a ella y consiste más en la excelencia del agente, y de otro lado, en los logros externos de su actividad u operación. Si se admite que estas dos vías han de correr paralelamente se entiende que las actividades con las que se consiguen bienes externos, conducen necesariamente a alcanzar bienes internos, pero este legado del pasado clásico, en su desarrollo histórico conlleva una dualidad o dialéctica con fuerte incidencia en el carácter específico del maestro de la modernidad.

Si se admite que lo que busca la educación es una seria colaboración con el ser del hombre, esto presupone toda su condición de persona humana como principio y término, donde la actividad humana cobra pleno sentido, no sólo como intervención de un agente sobre una materia sino sobre sí mismo, pues la naturaleza de una cosa es la misma esencia de ella, considerada como principio radical de sus operaciones propias. En consecuencia, ninguna clase de medida externa de carácter organizacional en educación, alcanza pertinencia sin una teoría fundante en lo humano, capaz de dar una respuesta al que, al cómo y al para qué meta debemos educar.

Lo anterior ha tenido que ver con el planteamiento de dos dominios: el clásico con el planteamiento del método inductivo - deductivo, y la tendencia contemporánea como una argumentación desde lo hipotético - deductivo. Tenemos así dos paradigmas de la epistemología, pero 
cada uno tiene sus propios límites, debiéndose señalar que estos ejercicios lógicos por sí solos no pueden dar la episteme, porque no dan garantía de verdad. La lectura de la realidad necesita en efecto de las dos miradas, tanto de la epagoghé de la que Aristóteles habla a propósito de la inducción, como de las intuiciones puras. Sería errado pensar alcanzar garantía de verdad, sólo por el hecho de saber formular leyes universales partiendo de casos particulares.

La concepción científica, refiere a características asociadas con el postulado según el cual un corpus de conocimiento o teoría, tiene un estatus de episteme. Pero no todas las cosas valiosas son conmensurables en estos términos. La primacía en una de estas vertientes hace que a finales del siglo XIX, la pedagogía entre en crisis cuando los fundamentos en los que se asentaba hasta entonces, la práctica, la observación y la inducción, sufren una inversión en su metodología acercando la pedagogía a otras ciencias y otras prácticas epistemológicas. Si antes el maestro era un conductor, un acompañante práctico, ahora ha de ser un científico a cuya sombra se alcanza el saber, un ser que profesa un saber es un profesor, que a modo de tutor lo demuestra.

Lo que de ahí en adelante se designa como educación depende de los acuerdos sobre los términos, de investigaciones particulares, así como de esbozos teóricos, mediante los cuales se trata de ordenar las ideas. La educación moral, especulativa y técnica no tiene ante sí otra ciencia pedagógica que no sea la metodología interesada únicamente por el aspecto técnico de la instrucción, en el fenómeno educativo y no específicamente en su naturaleza, que da cabida a un conjunto variado de ciencias pedagógicas particulares quedando la educabilidad -objeto formal del saber pedagógico- desfigurada al no hacer referencia a la ordenación natural de todo hombre a la perfección, ni a su indigencia en dicha tendencia. La educabilidad será entonces un concepto a acordar, a consensuar históricamente, actuará a modo de idea trascendental kantiana, es y será lo que queramos que sea, por esto existen tantas filosofías de la educación, así cada una tiene un concepto distinto de hombre y de educación. 
Si se admite que el objeto formal de una ciencia es el que da unidad a la misma, desvirtuado este objeto formal por la crítica demoledora de la racionalidad técnica, no queda más que el objeto material que es bien indeterminado, por esto terminan existiendo tantas ciencias de la educación, tantas opiniones, sobre el educando, sobre el educador, sobre el proceso educativo, sobre los medios, la institucionalidad. Tantas ciencias cuantos objetos puedan descubrirse en el fenómeno educativo. El educando que posee una naturaleza unitaria como persona, deberá soportar ideas educativas inconexas, parciales, fragmentarias, una acción educativa dispersa que puede desorientar, paralizar intelectualmente y en la acción práctica.

La argumentación pedagógica, pasa de ser una ciencia de lo humana a una ciencia social o de la productividad y la educación de una práctica silenciosa y sobre determinada por la pedagogía a ser una ciencia que incorpora la misma pedagogía. Esto hace que en el siglo XIX sea difícil diferenciar lo que es la pedagogía y lo que es la educación.

El terreno de las ciencias humanas y sociales es el terreno en el cual se dará la educación, pero sin sacarla de las ciencias de la naturaleza; es el campo de la complejidad. Así los problemas son el hombre y la democracia, el hombre y la verdad, el hombre y la experiencia. La enseñanza a partir de estos principios es del terreno del pensamiento complejo. Relaciones conceptuales, experiencia universal, evolución y desarrollo, y experiencias institucionales. Tanto las ciencias humanas y con ellas la educación, quedan ubicadas en un terreno bastante inestable como en efecto se siente hasta hoy.

En tal escenario, la comunidad académica ha de tener la capacidad de mirarse de forma desinhibida, sin dejar de lado los intereses que históricamente la han concebido, como intereses necesarios en orden a su idea y función que forman parte natural de la vida académica y de las contingencias de un discurso racional. La racionalidad implica como tal, un proyecto de emancipación e interacción entre los discursos 
sustentados, convalidados por una comunidad académica capaz de identificar distorsiones de la estructura de intereses de la sociedad.

Que el maestro sea un concepto, que la enseñanza además de noción sea un quehacer científico, que el niño, o joven sea una categoría abstractiva, resulta pedagógicamente un problema. El acto educativo, definido desde una objetivación, confunde al maestro, pues dicha complejidad es más propia del científico que de la práctica pedagógica, complejidad inmersa en el hallazgo del concepto, es decir, de la experiencia universal localizada.

La emergencia de la educación superior como sistema supuso no solo una reconvención de identidad, sino una lógica distinta que obliga a modificar la percepción y las prácticas del desarrollo del conocimiento.

De otra parte, la educación en general y particularmente el nivel superior, tanto por el contexto de la globalización, como por el espíritu de la sociedad de la información y del conocimiento, aparece como una institución clave de esta sociedad contemporánea. La sociedad moderna aborda otras definiciones de conocimiento y razonamiento.

El conocimiento en la sociedad moderna requiere una consideración especial. La novedad en esta afirmación está en que históricamente ha sido la educación superior quien ineludiblemente ha estado vinculada con el conocimiento, ella ha sido la encargada de su producción y comprensión por la investigación. Ahora es la sociedad la abanderada por aquellas formas de conocimiento que se pueden describir como operacionales, técnicas, computacionales o de pensamiento estratégico, es decir, relativas a la tecnología, la matemática o la informática, también aquellas que ayudan a la contabilidad, el planteamiento de problemas y a la administración. Esta tendencia por supuesto es una visión univocista del conocimiento. Prima la enseñabilidad a la educación misma. La educación sobre todo la superior, ya no posee ese ethos que le es propio, valioso en sí mismo. La capacidad concebida como competencia ya no 
es una cualidad intrínseca del desarrollo connatural de lo humano, es fácilmente equiparable a emulación o adiestramiento.

La profesionalización es una tarea importante de la universidad, pero no la esencial. Profesionales pueden adiestrarse incluso en instituciones que no tengan las características de educación superior, pero la tarea fundamental de la universidad es formar personas en el conocer y en el actuar, como buenos ciudadanos, críticos, independientes, con conciencia clara y con decisión ante las responsabilidades.

Como consecuencia se configuran no solo nuevas prácticas educativas sino nuevas expresiones de vida de los agentes universitarios, porque nuevas son las formas de su relación con las personas, con los recursos, con los medios, donde no se hacen extrañas las concepciones funcionalistas de la educación.

Privar al hombre de la posibilidad de su capacidad de verdad objetiva, de moralidad objetiva, de libertad objetiva, es su peor mal, el conocimiento como la acción humana se empobrecen y se achican. El conocimiento se convierte en simple información y la acción, en simple trabajo. Se pierde o se reduce la visión de las acciones humanas, como un asunto complejo y se reducen a un solo aspecto del despliegue de la acción: al producto mismo, que en el caso de la educación es el resultado ante el cual es viable la medición, la acreditación, el ranquin.

Estas incorporaciones implican grandes modificaciones prácticas para la vida de los maestros. La filosofía de la educación superior, en su campo de estudio, ha pasado de explicar y ordenar el quehacer educativo formativo a arbitrar la considerable manifestación de ciencias fenoménicas, dado que no es posible encontrar una esencia común.

Mientras los antiguos toman como punto de partida el "saber cómo se puede vivir en conformidad con el orden dictado por la naturaleza" ahora se parte del planteamiento del dominio técnico de la naturaleza. Del escenario educativo partícipe de esta cosmovisión, puede surgir un 
hombre "racionalizado" o "ilustrado" un tipo de hombre orientado al dominio del mundo con una mentalidad funcional y unas motivaciones morales autónomas, en una sociedad económica y burocrática, un ámbito que va moldeando estilos y formas de vida, alimentadas muchas de las veces desde lo educativo.

Al fondo del debate, se asoma una sociedad para quien la transferibilidad de la productividad, la búsqueda de fuentes de riqueza y de empresa es lineamiento para la educación superior.

Al hablar de educación en tanto formación, se habla de educido, cuando la forma está en potencia en algún sujeto ya existente, del cual se saca (educere). Así, si la educción es sustancial se habla de una generación. Lo contrario si es una forma accidental, se habla de una alteración. Las acciones inmanentes exigen, que el efecto se dé en el mismo sujeto que es su causa. El sujeto que se educa es la causa eficiente de su educación. Lo contrario son actor educativos que no van más allá de solas alteraciones.

Aquí parece estar el punto fuerte del análisis del concepto de formación en la perspectiva de Tomás de Aquino, quien precisamente utiliza para la definición de educación con frecuencia el concepto de educere. Es un proceso que debe conducir a excitar desde adentro del individuo toda virtualidad y posibilidad en estado germinal y que se debe sacar a flote para su proceso de realización personal y elevarse así a la plenitud de su ser.

Desconocer el proceso de la causa eficiente de la educación puede tener graves consecuencias. Un educador desdibujado, indefinido, pierde su capacidad de actuar sobre el educando, disipándose su perfectividad; el agente que lo sustituya no lo hará entonces desde la educabilidad, sino desde cualesquiera otras razones o técnicas o mera enseñabildad, o el imperio del método, que no se ocupan explícitamente o en primera instancia de la idea de formar a la persona desde una pedagogía sensata. Se pierde en el alumno aquella fuerza creadora de ser causa sui. 
Un mayor protagonismo reflexivo del educador en su trabajo, significa que la práctica educativa no es una mera cuestión técnica instrumental, sino una forma de praxis dirigida y decidida deliberativa y éticamente.

J. Saramago (2010) expresaba cómo la universidad es el último tramo formativo en el que el estudiante se puede convertir, con plena conciencia, en persona madura, en ciudadano. Hoy tendríamos que añadir además toda la educación pos graduada dentro y fuera de la misma universidad. Con todo, esta sigue siendo "el lugar de debate, donde por definición, el espíritu crítico tiene que florecer, un lugar de confrontación de ideas y construcción de las propias” Saramago (2010). Por supuesto esto pone de manifiesto que no se trata solo de instruir, sino de formar y desde dentro, solo así se puede incidir en el progreso y bienestar de la sociedad.

\section{Referencias}

Alvira, R. (1980). Nota sobre la relación entre algunos conceptos fundamentales del pensamiento moderno. En Ética y teología ante la crisis contemporánea. Pamplona, España: Eunsa.

Anscombe, E. (2000). Intenction. (2a ed.). Brasil Blachwell, Oxford, 1963). Mass. Harvard University Press.

Aquino, T. (2010). Comentario a la Ética a Nicómaco de Aristóteles (Libro VI, lección VII Números 862-865). (3 ${ }^{\mathrm{a}}$ ed.). (Trad. A. M. Mendoza). Pamplona, España: EUNSA.

Arendt, H. (2008). La condición humana. (I. d. Cruz, Trad.). Barcelona. Paidós.

Aristóteles. (1970). Ética a Nicómaco. (Trad. e. b. Marías). Madrid: Gredos.

Aristóteles. (2004). Metafísica. (Trad. t. H. Zucchi). Buenos Aires: Debolsillo. 
Bárcena, F. (1991). Teoría de la educación y conocimiento práctico. Sobre la racionalidad práctica de la acción educativa. Revista Complutense de Educación, 2, 221- 243.

Barnett, R. (2001). Los límites de las competencias. Barcelona: Gedinsa.

Berandi, F. (2003). La fábrica de la infelicidad. Nuevas formas de trabajo y movimiento global. Madrid: Traficantes de Sueños.

Beuchot, M. (2011). Epistemología y hermenéutica analógica. Potosí: Editorial Universitaria Potosina.

Brunschwig, J. (2000). Diccionario Akal de El saber griego. "El Conocimiento” (pp. 85 ss.). Madrid: Akal.

Canals, F. (1981). Cuestiones de fundamentación. (pp.100-101). Barcelona: U. de Barcelona.

Cardona, C. (1973). Metafísica de la opción Intelectual. Madrid: Rialp.

Carpio, P. (2004). Principios de filosofía. Una introducción a su problemática. Buenos Aires: Glauco.

Castells, M. (1996). La era de la información. Economía, sociedad y cultura. Madrid: Alianza Editorial.

Derrida, J. (2001). La universidad sin condición. París: Galilée.

Dienelt, K. (1980). Antropología pedagógica. (Trad. T. A. Alcoba). Madrid: Aguilar.

Durkheim, E. (1975). Education et sociologie. (Trad. J. Muls). Barcelona: Península. 
Durkheim, E. (1999). La educación, su naturaleza y su papel y Naturaleza y método de la pedagogía. En Educación y sociología. Buenos Aires: Altaya.

Foucault, M. (1977). La arqueología del saber. (Trad. A. G. Camino). México: Siglo XXI.

Gadamer, H. G. (1991). Verdad y Método I- II. Salamanca, España.

García, M. (1975). Lecciones preliminares de filosofía. (9a ed.). Madrid.

Giddens, A. (1997). Consecuencias de la modernidad. Madrid: Alianza Editorial.

Gómez, J. (2001). El Cristianismo y la filosofía moral cristiana. En V. Camps. Historia de la Ética V. Tomo 1. (pp. 282-344). Barcelona: Crítica.

Habermas, J. (1982). Conocimiento e interés. (Trad. J. F. Manuel Jiménez). Madrid: Taurus.

Hallak, J., Poisson, M. (Coords.). (2007). Escuelas corruptas, universidades corruptas: ¿Qué se puede hacer? Unesco. París.

Heidegger, M. (2003). Filosofía, ciencia y técnica. Santiago de Chile: Universitaria.

Horkheimer, A., y Adorno. (1999). Dialéctica de la Ilustración. Barcelona: Círculo de Lectores.

Hoyos, G. (2001). Ciencia y tecnología entre la crítica y la ética: el uso pragmático de la razón práctica. En J. A. López y J. M. Sánchez (eds.). Ciencia, tecnología, sociedad y cultura en el cambio de siglo. Madrid: Ed. Biblioteca Nueva. 
Hutchins, R. (1959). La universidad de utopía. (pp. 30-31). Buenos Aires: Editorial Universitaria de Buenos Aires.

Kant, I. (2000). Crítica de la razón práctica. Conclusiones. Madrid: Alianza Editorial.

Kant, I. (2003). La pedagogía. Madrid: Akal S.A.

Kenny, A. (2000). Tomás de Aquino y la mente. Barcelona: Herder.

Levy, P. (2004). Inteligencia Colectiva. Recuperado el 14 de agosto de 2012, de ebookbrowse.com: http://ebookbrowse.com/p-levyinteligencia-colectiva-pdf-d89816652

Lyotard, J. F. (1998). La condición postmoderna. Informe sobre el saber. (p. 14). Madrid: Ediciones Cátedra.

Llano, A. (1983). Gnoseología. Pamplona: Eunsa.

Llano. C. (2007). Sobre la idea práctica. Pamplona, España: Eunsa.

Lobato, A. (Dir.). (1994). El hombre en cuerpo y alma. Valencia, España: EDICEP C.P.M.

Mardones, J. (1988). Postmodernidad y cristianismo, el desafío del fragmento. Santander, España: Sal Terrae.

MacIntyre, A. (1994). Justicia y racionalidad. Conceptos y contextos. (p. 137). (Trad. T. d. Sisón). Barcelona: EUNSA.

MacIntyre, A. (2001). Tras la virtud. (Trad. A. Valcárcel). Barcelona: Crítica.

MacIntyre, A. (2004). Críticas a la modernidad. (p. 24). Londres: Routledge.

Martínez,A.(2004). De la escuela expansiva a la escuela competitiva. Dos modos de modernización en América Latina. Barcelona: Átropos. 
Martínez, E. (2002). Persona y educación en Santo Tomás de Aquino. Madrid: Fundación Universitaria Española.

McLuhan, M. (1994). Comprender los medios de comunicación. (p. 95). (Trad. P. Ducher) Barcelona: Paidós.

McLuhan, M. (1997). El medio es el mensaje. Barcelona: Paidós.

Meillet, A., \& Ernout, A. (1979). Diccionnaire Étymologique de la langue Latine. Historie de mots, 4. París: Ed. Klincksleck. F.

Mill, J. S. (1831). The Spirit of the Age (El espíritu de la época).

Millán-Puelles, M. (1958). Los límites de la educación en Karl Jaspers. En La claridad en filosofia y otros estudios. Madrid: Rialp.

Naishatat, F. S. (2000). Recuperado el 23 de septiembre de 2012, de http://webiigg.sociales.uba.ar/Epistemologia/so90/quienes.htm

Nussbaum, M. (2011). Sin fines de lucro. Porqué la democracia necesita de las humanidades. Bogotá: Panamericana.

Quiceno, H. (1998). De la pedagogía como ciencia a la pedagogía como acontecimiento. Revista Educación y Pedagogía 19 y 20, p. 137158. Grupo Federici. Universidad Nacional. Recuperado de http:// ayura.udea.edu.co/publicaciones/revista/revista19-20.pdf

Reale, G. (1997). Introduzione a Aristotele. (p. 159). Roma: Laterza.

Renaut, A. (2008). ¿Qué hacer con la universidad? Buenos Aires: UNSAM edita.

Restrepo, A. (2014). La acción humana en perspectiva prudencial, valor y alcance para la educación superior. USTA. Bogotá.

Rodríguez, A. (2008). Legitimación teórica de la praxis en el pensamiento aristotélico. Revista Philosophica, 34 [Semestre II], 57-68. 
Roldán, D. A. (2010). La relevancia de la phronesis en la ética aristotélica. Introducción a algunos aspectos de su vigencia. Teología y Cultura, 37-52.

Rorty, R. et al. (2001). Cultura y modernidad: perspectivas filosóficas de Oriente y Occidente. Barcelona: Kairós.

Sanabria, J. R. (2001). Ética y postmodernidad. DIKAIOSYNE, 6, 93-121. Revista de filosofía práctica.

Saramago, J. (2010). Democracia y universidad. Madrid: Editorial Complutense.

Segura, A. (1994). El alma humana. En El hombre en cuerpo y alma (t. I). Valencia, España: Edicep.

Sen, A. (2010). Los fines y los medios del desarrollo. Recuperado el 10 de octubre de 2012, de http://inti.gob.ar/bicentenario/documentoslibro/ pdf/anexo_1/los_fines_y_los_medios_del_desarrollo.pdf.

Tobón, S. (2006). Competencias en la educación superior. Política hacia la calidad. Bogotá: Eco Ediciones.

Virno, P. (2003). Gramática de la multitud. Para un análisis de las formas de vida contemporánea. (Trad. A., Gómez). Stanford, California: Creative Commons.

VV. AA. (2002). Historia de la ética, 1. De los griegos al Renacimiento. (V. Camps, ed.). Barcelona: Crítica.

William, J. (1962). Historia de la filosofia griega (vol. I, p. 399). Cambridge: University Press.

Wittrock, B. (1991). ¿Dinosaurios o delfines? Origen y desarrollo de la universidad orientada hacia la investigación. Revista de Educación, (296), 73-97. 
Este libro se editó en la Universidad Santo Tomás Seccional Bucaramanga

en marzo de 2017 
